\title{
The Gut Microbiota: Ecology and Function
}

\section{Benjamin P. Willing ${ }^{1}$ and Janet K. Jansson ${ }^{2}$}

${ }^{1}$ Michael Smith Laboratories, University of British Columbia, Vancouver, BC, Canada V6T 1 Z4.

${ }^{2}$ Department of Ecology, Earth Sciences Division, Lawrence Berkeley National Laboratory, Berkeley, CA 94720. J.K. Jansson's work is partially supported by the U.S. Department of Energy and LBNL under Contract No. DEAC02-05CH11231. 
The gastrointestinal (GI) tract is teeming with an extremely abundant and diverse microbial community. The members of this community have coevolved along with their hosts over millennia. Until recently, the gut ecosystem was viewed as black box with little knowledge of who or what was there or their specific functions. Over the past decade, however, this ecosystem has become one of fastest growing research areas of focus in microbial ecology and human and animal physiology. This increased interest is largely in response to studies tying microbes in the gut to important diseases afflicting modern society, including obesity, allergies, inflammatory bowel diseases, and diabetes. Although the importance of a resident community of microorganisms in health was first hypothesized by Pasteur over a century ago (Sears, 2005), the multiplicity of physiological changes induced by commensal bacteria has only recently been recognized (Hooper et al., 2001). The term "ecological development" was recently coined to support the idea that development of the GI tract is a product of the genetics of the host and the host's interactions with resident microbes (Hooper, 2004).

The search for new therapeutic targets and disease biomarkers has escalated the need to understand the identities and functions of the microorganisms inhabiting the gut. Recent studies have revealed new insights into the membership of the gut microbial community, interactions within that community, as well as mechanisms of interaction with the host. This chapter focuses on the microbial ecology of the gut, with an emphasis on information gleaned from recent molecular studies.

\section{MEMBERSHIP (WHO IS THERE)}

In most animals studied to date, the microbial community in the most densely populated regions of the GI tract is dominated by bacteria with total cell counts reaching as high as a hundred 
billion cells per gram of digesta (Hooper and Gordon, 2001a). In humans, this number is equivalent to approximately $1 \mathrm{~kg}$ of the human mass. The gut is also colonized by microbes from the domain Archaea and eukaryotes including protozoa, yeast, and fungi. However, only an estimated $20 \%$ to $25 \%$ of the gut inhabitants have been cultured to date. Therefore, most recent studies have used molecular approaches to identify community members in the gut. This research area has resulted in the terms microbiome (referring to collective microbial genes in the community) and microbiota (referring to the collective microorganisms present in the community). Most attention has been devoted to bacterial components of the gut microbiota and, thus, they are the focus of this chapter.

The indigenous microbiota that colonizes the GI tract comprise the resident, autochthonous members of the community and are also referred to as the commensal microbiota. The commensal relationship implies that one member of the association benefits while the other is unaffected. However, in most cases, this is a mutualistic relationship. The microbiota benefit from the host that provides a nutrient rich and hospitable environment, while the microbiota provide nutrients that would not otherwise be available to the host, regulate immune development, and create a barrier to infection from pathogens. There are also transient (allochthonous) bacteria that are regularly ingested, but are unable to colonize the gut under normal conditions (Berg, 1996). This is not to say that allochthonous organisms cannot have an effect on the host. The majority of probiotic bacteria would be considered allochthonous - when the host ceases to consume the live organisms they are transient and do not persist at high levels.

\section{Methods to Analyze the Microbiota}

Until the late 1990s, the microbiota of the GI tract was nearly exclusively studied using selective 
culture techniques. The inability to culture the majority of gut microbes because of unknown growth requirements and potential dependence on co-colonizing bacteria or host factors (Zoetendal et al., 2004), spurred the establishment of molecular-based approaches as the new standard. Most molecular approaches utilize the $16 \mathrm{~S}$ rRNA gene as a phylogenetic marker because of its genetic stability and composition of conserved and variable regions (Woese et al., 1990). The establishment of public databases of $16 \mathrm{~S}$ rRNA gene sequences (http://rdp.cme.msu.edu/ and http://www.ncbi.nlm.nih.gov/) from cultured organisms allows for taxonomic classification of uncultured bacteria. Because of the complexity of the bacterial community in the gut, the method used for its study depends on the question being asked. An overview of different molecular "omics" approaches to study the gut microbiota is shown in Figure 1.

To examine overall changes in the microbial community a number of fingerprinting approaches have been developed. These techniques are also collectively referred to as "microbiomics," which attempts to study the identities of members of complex microbial communities. Most microbiomics approaches for bacterial identification are based on sequences from the variable regions of the $16 \mathrm{~S}$ rRNA gene. The most frequently used techniques include terminal restriction fragment length polymorphism (T-RFLP), denaturing gradient gel electrophoresis, and cloning and sequencing (Fig. 1). These methods take advantage of the conserved regions of the $16 \mathrm{~S}$ rRNA gene as they utilize PCR primer binding sites that are present in all bacteria. Denaturing gradient gel electrophoresis separates PCR amplified DNA molecules based on their ability to migrate through a polyacrylamide gel that contains a denaturant. The extent of migration is dependent on the DNA sequence of amplicons produced via PCR. As the strands become denatured and separate, they become less mobile in the gel. One end of each 
amplicon is held together with a GC clamp to prevent complete strand separation. The resulting output is a series of bands on a gel that can subsequently be excised and sequenced to determine the identities of the populations corresponding to individual bands. In T-RFLP, the variability in lengths of restriction-digested PCR products is visualized by capillary-based DNA sequencing. One primer, normally at the $5^{\prime}$ end of the amplicon, has a fluorescent label to enable the terminal restriction fragment to be detected by the automated sequencer. Because of its relatively high throughput and high reproducibility, this technique is often the method of choice for comparison of multiple samples over time or different treatments (Dicksved et al., 2007). Although both methods give insight into overall changes in the microbial population, their taxonomic resolution is relatively poor.

Clone libraries of PCR amplified 16S rRNA genes have greater taxonomic resolution; however, they are limited by the sequencing costs, although some large studies have achieved as many as 10,000 to 20,000 sequences (Eckburg et al., 2005). The recently developed 454 pyrosequencing approach, using multiple sequence tags or barcodes, allows for relatively deep sequencing of multiple samples in parallel at fairly high taxonomic resolution, although not at a level equal to that of full-length 16S rRNA sequencing (Sogin et al., 2006; Andersson et al., 2008). The power of this method was recently demonstrated in a sequencing study of human fecal samples that resulted in 440,000 reads with an average read length of $59 \mathrm{bp}$ (Dethlefsen et al., 2008). This study revealed 5,600 operational taxonomic units (OTUs) at $99 \%$ identity from only 3 individuals. Furthermore, advances in pyrosequencing enable longer read lengthsapproximately $250 \mathrm{bp}$ on the 454 GS-FLX platform and approximately $450 \mathrm{bp}$ on the 454 GSTitanium platform. The Roche 454 pyrosequencing technology is continuing to improve with longer read lengths, thus improving taxonomic resolution. Other promising second generation 
sequencing approaches that have yet to be applied for detailed studies of the human gut include the Illumina Solexa platform and the SOLiD platform by Applied Biosystems. Another recent fingerprinting approach to assess the gut microbial community composition uses a phylogenetic microarray. The Phylochip is a microarray that contains oligonucleotide probes designed based on all environmental sample sequences submitted to the RDP website. These sequences have passed a quality check and are deposited in the Greengenes database, http://greengenes.lbl.gov/cgi-bin/nph-index.cgi (Yergeau et al., 2009). The HITChip is another phylogenetic microarray that specifically contains probes for sequences isolated from the human intestinal tract (Rajilic-Stojanovic et al., 2009). Although much improved over previous culturebased methods, all of the microbiomics approaches introduce biases because of cell lysis and DNA extraction, primer design and binding, PCR, sequencing (e.g., homopolymers produced during 454 pyrosequencing), and/or cloning.

For the quantification of specific bacterial groups, or species, fluorescence in situ hybridization (FISH) and quantitative real-time PCR have most commonly been applied. Both approaches utilize the variability within the 16S rRNA gene for the development of specific primers or probes that only amplify or hybridize to the regions of the 16S rRNA gene that distinguish a specified target group or species. Primers and probes for both methods can be generated using software such as the ARB Project (http://www.arb-home.de). FISH can also be used to visualize the localization of bacteria within the gut, giving insight into which bacteria are in close proximity with the mucosal surface (Johansson et al., 2008). Another advantage of FISH over other molecular approaches is that it does not depend on DNA purification or amplification, thus avoiding many of the biases mentioned previously. FISH, however, does have its own disadvantages. For example, because only a few probes can be used simultaneously, it is limited 
in its ability to target many different bacteria in the same sample. Also, FISH is relatively technically demanding method and there can be problems in distinguishing fluorescent cells over background fluorescence in samples.

Quantitative PCR overcomes many of the disadvantages of using FISH and can be used for accurate quantification of a specific 16S rRNA target. Group- or species-specific primers can be designed to specifically quantify certain members of the microbiota. For example, Willing et al. (2009a) used specific primers to quantify populations of Escherichia coli and Faecalibacterium sp. in fecal samples and intestinal biopsies.

Although the methods described here provide a means to determine the composition of members of the gut microbiota, there is also interest in the functional characteristics of the community. Although a certain level of prediction can be achieved by extrapolating to physiological properties of related cultured species, this approach is challenging and, in many cases, inaccurate. Metagenomic analysis of the microbiota gives sequence information from the collective genomes of all members of the microbiota (microbiome). The first metagenomic study of the human gut resulted in 78 million base pairs of DNA sequences from two American individuals (Gill et al., 2006). This study cataloged the combined gene complement of the microbiome, including functional genes. However, it is important to keep in mind that some of the DNA analyzed may have been derived from inactive, dormant, or even dead members of the community. Also, not all genes are expressed at any given time and condition. Therefore, metagenomic approaches only provide information about functions that have the potential to be expressed.

Other "omics" approaches, such as metatranscriptomics, metaproteomics, and metabolomics, enable different levels of expression to be studied and a more direct assessment of 
which processes are active and functioning in the gut under a given condition. Some results using these different approaches will be discussed later in the context of relevant subsections.

\section{Identification of Microorganisms in the Gut}

Microbiomic studies, primarily those targeting bacteria, have been used to study the composition of the gut microbiota in humans and some animals. A recent study examined the microbial composition of 60 divergent animal species found in zoos and in the wild (Ley et al., 2008). Of more than a 100 known bacterial phyla (divisions), representatives of only 17 were detected in this diverse set of fecal samples (Table $1<\mathrm{TAB} 1>$ ). This relatively restricted representation of bacterial phyla suggests that the gut microbiota coevolved with their mammalian hosts. The Firmicutes phylum was the only phylum detected in all animal species and was also the most abundant, representing nearly $67 \%$ of all classified sequences. Other highly represented phyla included the Bacteroidetes, Proteobacteria, Actinobacteria, Verrumicrobia, and Fusobacteria. The remaining 11 phyla represented less than $0.5 \%$ of the classified sequences. The functions of most of these less prevalent species have not been specifically identified and it is not known if the rare members of the microbiota have important roles. Current studies suggest, however, that the dominant phyla are best adapted to the gut environment. Although, in the study by Ley et al. (2008), there were many similarities between animal species and within species-each individual studied also harbored at least one unique OTU (at 96\% similarity) that was not found in any other sample. On average, $62 \%$ of the OTUs from a given animal species were unique to that species.

There have been additional studies of the bacterial composition of the gut in other animals, including chickens (Dumonceaux et al., 2006), mice (Yap et al., 2008), pigs (Hill et al., 
2005), and cows (Hernandez et al., 2008). These studies have revealed that each animal species has a gut microbiota that is unique and representative of that species. This is exemplified by a recent study of the horse microbiota that found that less than $33 \%$ of $16 \mathrm{~S}$ rRNA clones had matches in databases at the species level, with a species being defined at 98\% 16S rRNA sequence homology (Willing et al., 2009b). Because it is not feasible to discuss the microbiota of all mammals in the scope of this chapter, we will focus on the GI microbiota of humans, including specific examples from other species that have been relatively well studied, such as the mouse and pig.

The human fecal microbiota is dominated by two bacterial phyla: the Firmicutes and Bacteroidetes (Eckburg et al., 2005). Approximately 800 to 1,000 different bacterial species and more than 7,000 strains inhabit the human GI tract, based on estimates of 16S rRNA libraries from fecal samples (Backhed et al., 2005). The application of second generation sequencing approaches, such as 454 pyrosequencing of $16 \mathrm{~S}$ rRNA genes, has provided a greater depth of view of the composition of the gut microbiota (Andersson et al., 2008). One pyrosequencing study revealed as many as 3,300 unique OTUs in a single individual (Dethlefsen et al., 2008). As fecal samples from more individuals are being sequenced, it is becoming apparent that each individual has a relatively unique gut microbiota. This, in turn, presents a major challenge when trying to design studies and trying to apply general ecological rules to better understand the functional roles of the gut microbiota.

\section{Core Microbiome}

Given the great variability in gut microbiota between individuals, a question has been raised whether there is a "core microbiome," or a set of microorganisms that is found in all individuals. 
One study of 17 subjects looking to define the phylogenetic core found that there were no OTUs, defined at $2 \%$ dissimilarity, that could be found in all subjects sampled, suggesting that the concept of a core microbiome is likely invalid (Tap et al., 2009). However, other sequencing studies suggest that a core microbiome exists at the gene level, including important components of various metabolic functions (Turnbaugh et al., 2009). However, a "functional core" can be potentially defined. Although the study by Turnbaugh et al. (2009) revealed substantial variation in the relative amounts of the key phyla-Firmicutes, Bacteroidetes, Actinobacteria, and Proteobacteria - there was very little variation in function, based on the categories of gene function, in the same samples analyzed (Fig. 2). These results suggest that, although the composition of the gut microbiota is variable, there likely remains functional redundancy in the community, which may be a protective mechanism to perturbation.

\section{The Archaea}

Members of the Archaea, particularly methanogens, have been found in the intestinal tract of many vertebrate species (Lin and Miller, 1998). In humans, methanogens can represent as much as $10 \%$ of the anaerobic microorganisms in the adult colon and are dominated by a single species, Methanobrevibacter smithii (Eckburg et al., 2005). The genome sequence of this microbe has revealed that it is specifically adapted to the human gut environment (Samuel et al., 2007). Other minor representatives of Archaea in the gut include Methanosphaera stadtmanae and the Crenarchaeotes (Rieu-Lesme et al., 2005). These methanogens play a vital role in the gut by removal of $\mathrm{H}_{2}$ via anaerobic metabolic processes. However, not all humans produce methane gas in their intestines but, rather, utilize other $\mathrm{H}_{2}$ disposal routes, as discussed later (Walker, 2007). 
The gut environment from other hosts - including the horse, pig, cow, rat and goosehave been shown to contain Archaea in the genus Methanobrevibacter that have high sequence similarity to the $16 \mathrm{~S}$ rRNA gene from $M$. smithii. This suggests that methanogens inhabiting the gut environment share a common descent. However, sheep isolates from one study were sufficiently divergent to suggest a separate line of descent within the genus Methanobrevibacter (Lin and Miller, 1998). Methanogens are of particular importance in ruminant microbiology. The production of methane by gut fermentation reactions results in reduced metabolic efficiency, with up to $13 \%$ of the energy from the diet being lost to methane production, as well as an environmental concern because of the role of methane as a greenhouse gas (Ohene-Adjei et al., 2008). Efforts are currently underway to limit the abundance and activity of methanogenic Archaea to reduce the impact of beef production on global warming (Hook et al., 2009).

\section{Intestinal Fungi}

Recent studies have begun to reveal the identities of fungi in the intestinal tract. One study identified a wide variety of fungi in mouse feces, but it was not determined whether they were colonizing commensals or simply transient organisms attached to dietary particles (Scupham et al., 2006). Repeated sampling of the human gut indicated that some fungi were temporally stable and actually colonized the intestine (Scanlan and Marchesi, 2008). Similar to bacteria, there is a great disparity between what can be cultivated and what can be detected using DNA-based methods. The cultivable fraction of the fungal microbiota in human feces is dominated by Candida spp. strains (Scanlan and Marchesi, 2008), whereas culture-independent analysis revealed that members of the genera Gloeotinia/Paecilomyces and Galactomyces were the most abundant (Scanlan and Marchesi, 2008). However, the diversity and abundance of fungi in the 
GI tract is quite low relative to that seen with the bacteria. Although relatively unexplored, specific fungal populations may play important roles in the gut. This is suggested by a recent study that found an increased abundance of host antibodies specific to Saccharomyces cereviceae in patients with Crohn's disease (Dossopoulos et al., 2007).

\section{LOCALIZATION OF GUT MICROBIOTA}

Microbes survive within many microhabitats in the digestive tract, including the intestinal lumen, the mucus layer lining, and other varying compartments of the GI tract (Mackie et al., 1999). The bacterial population of the GI tract increases in density and complexity from proximal to distal regions, with the exception of the mouth, and changes composition with location and time (Fig. 3). The stomach and duodenum have a relatively low microbial density, with $10^{3}$ to $10^{5}$ CFUs per gram of contents, and a population dominated by the Lactobacillus, Streptococcus, and Enterococcus genera. This community is limited in density and diversity because of an acidic environment and the presence of bile secretions. Because the rate of digesta passage is rapid through this region, the ability to attach to and colonize the mucosal layer appears to be important in the proximal small intestine (SI). The rate of digesta passage slows in the distal SI and bacterial counts increase to $10^{8}$ to $10^{9} \mathrm{CFU}$ per gram of contents accordingly. Phylogenetic representation in the distal SI also increases and includes those genera indicated previously, plus members of genera within the Clostridiales and Bacteriodetes families (Hill et al., 2004;

Richards et al., 2005). Complexity of the microbial community is greatest in the large intestine, where the density increases to $10^{10}$ to $10^{12} \mathrm{CFU}$ per gram and the community is dominated by gram-positive genera, including Clostridium, Bacillus, Ruminococcus, and Fusobacterium (Hill et al., 2002; Leser et al., 2002). Variation within bacterial species among locations in the GI tract 
also substantially contributes to overall gut microbial diversity and function (Dixit et al., 2004). For example, fermentation of carbohydrates and amino acids are functions that become more prominent in the distal locations of the gut than in proximal regions (Cummings and Macfarlane, 1991).

The mucous layer covering the epithelial layer is made up of two distinct layers, referred to as loosely and firmly bound mucous layers. In situ hybridization studies have revealed that bacteria do not reside in the firmly bound mucous layer (Johansson et al., 2008). In contrast, the loosely bound mucosal layer contains abundant bacteria (Fig. 3). Attachment to the mucosa has been shown to be dependent on a variety of bacterial cell surface ligands (Sillanpaa et al., 2000; Roos and Jonsson, 2002), as well as specific receptors such as sugar chains of glycolipids or glycoproteins produced by host cells. The firmly bound mucous layer is extremely important for animal health as evidenced by studies of mice lacking the MUC2 gene, the major mucin of the colon mucus. These mice have bacteria in direct contact with the epithelial layer that results in inflammation and cancer development (Johansson et al., 2008). Although potentially not in continuous direct contact with the intestinal epithelium, substantial bacterial populations live in close proximity in the mucin layer and likely have intermittent direct contact. The abundance of bacteria in close proximity to the intestinal epithelium has been demonstrated by measuring microbial populations present in homogenized whole tissues after the intestinal contents have been eradicated by washing (Frece et al., 2005). The discrepancy observed between attachment in vitro and in vivo may be a consequence of the static nature of in vitro cell lines and the fact that tissue cultures lack other important host factors that keep the intestinal microbiota at bay. Conversely, the recent observation that bacteria are not directly associated with the intestinal epithelium may be a consequence of tissue collection conditions and assay sensitivity. Although 
the extent to which commensal bacteria come in direct contact with the intestinal epithelium is not clear, these bacteria clearly have major effects on the host.

\section{SUCCESSIONAL CHANGES}

At birth, the neonate leaves the sterile environment of the uterus and is immediately introduced to a population of bacteria in the vaginal tract and, subsequently, in the surrounding environment (Tannock et al., 1990a, 1990b). Analogous to the gradual establishment of pioneer microorganisms and species succession after a forest fire, there are early colonizers that quickly colonize the vacant system. These early colonizers are facultative anaerobes that create a reduced environment that is more favorable to growth by anaerobic species (Stark and Lee, 1982) and are eventually supplanted by their successors. The ecological succession of the commensal microbiota is relatively poorly understood in most species. The distal colon of the pig is colonized with $10^{9}$ to $10^{10}$ bacteria per gram of digesta within $12 \mathrm{~h}$ of birth (Swords et al., 1993). Clostridium spp. become dominant after 5 days of age, begin to decline at weaning, and are eventually replaced by Bacteroides spp., the dominant adult colonic microbiota in the pig (Swords et al., 1993). The diversity and activity of a given genera also change through time, particularly at weaning (Janczyk et al., 2007).

It is not clear whether microbial succession patterns in the proximal SI mirror those observed in the colon and feces. However, molecular based profiling studies in the pig have demonstrated marked differences in microbial composition between proximal and distal intestinal locations (Konstantinov et al., 2004; Hill et al., 2005; Richards et al., 2005).

There have also been some studies of succession in humans. However, they are limited to the fecal microbiota for obvious reasons. As discussed in the section about diet, some dramatic 
differences have been observed in the gut microbiota of infants that are fed formula compared to infants that are breast-fed (Harmsen et al., 2000). Other factors affecting succession patterns of the microbiota include method of delivery (vaginal vs. Caesarean section), postnatal hygiene, environment, and antibiotic use (Gronlund et al., 1999; Schwiertz et al., 2003; Lofmark et al., 2006).

\section{IMPACT OF ANTIBIOTICS}

Although there is great variation in the composition of the gut microbiota between individuals, within a given individual the composition is relatively stable and resilient over time. However, antibiotic administration can cause major disruptions in the gut microbiota. Of course, the reason that antibiotics are administered in the first place is to reduce levels of pathogenic populations that are detrimental to the host. Different specific bacterial populations may be targeted depending on the antibiotic that is administered. However, antibiotics also have a positive or negative impact on other nontarget members of the commensal microbiota. Microbes that are resistant to the antibiotic used have a selective advantage and may increase in numbers relative to susceptible strains. Alternatively, nontarget susceptible populations may be reduced in numbers upon antibiotic treatment.

In general, the diversity of the gut microbiota is reduced following administration of antibiotics (Jernberg et al., 2007), but this reduction is short lived and usually lasts only a matter of weeks or days. Relatively soon after antibiotic treatment is discontinued the commensal gut microbiota present before disruption return, for the most part, relatively quickly (Dethlefsen et al., 2008). However, some members of the bacterial community remain disrupted for long periods of time, even several years after antibiotic treatment (Jernberg et al., 2007). This is 
particularly the case for bacterial populations that are targeted by clindamycin (Lofmark et al., 2006; Jernberg et al., 2007). For example, a conventional 7-day administration of clindamycin was found to alter the ecology of the gut microbiota up to 2 years posttreatment (Jernberg et al., 2005; Lofmark et al., 2006; Jernberg et al., 2007). Our recent 454 pyrosequencing studies have also shown that the gut microbiota is dramatically perturbed for up to 4 years posttreatment after taking the common triple therapy for Helicobacter pylori (clarithromycin, metronidazole, and omeprazole) (Jakobsson et al., submitted).

In addition to disturbances in the ecology of the microbiota, antibiotics can also select for persistence of antibiotic resistance genes in the host. Studies have shown that several antibiotic resistance genes are stably maintained in the GI tract once they are acquired (Shoemaker et al., 2001). These genes are often carried on conjugative elements and, under selection pressure, they have the potential to be transferred between different species within the densely populated gut microbial community. Jernberg et al. (2007) used real-time PCR to quantify different resistance genes in DNA extracted from feces. They reported that clindamycin exposure led to significant increases of $\operatorname{erm}(\mathrm{F}), \operatorname{erm}(\mathrm{G})$, and $\operatorname{erm}(\mathrm{B})$ in feces. High levels of these resistance genes could still be detected 2 years after the antibiotic treatment had ceased. This is disconcerting considering the growing problem with increasing prevalence of antibiotic-resistant strains that are not susceptible to current arsenals of antibiotics.

\section{ADAPTATIONS OF THE COMMENSAL MICROBIOTA TO THE GUT ENVIRONMENT}

Increasing evidence suggests that the human gut, no matter the diet or region of the world, is consistently colonized by the same bacterial phyla and only a single division of Archaea. This 
indicates that only certain divisional members have evolved close associations with the human gut (Eckburg et al., 2005). What are the mechanisms that govern membership of the community as well as relative abundances of the members? Microbes colonizing the GI tract are not simply there as a matter of chance. Based on studies of a wide variety of animal species, it is apparent that the microbiota has truly coevolved along with the mammalian host and is highly specialized to thrive in the gut environment. The complement of genes represented in the gut microbiome is estimated to be 100 times the number of genes found in the host (Backhed et al., 2005) and is enriched in genes for glycan, amino acid, and xenobiotic metabolism; methanogenesis; and synthesis of vitamins and isoprenoids (Gill et al., 2006). The gut microbiome also has a diverse repertoire of environmental sensors and cognate regulators (Xu et al., 2007). Interestingly, motility and chemotaxis are two characteristics that seem to be underrepresented among gut microbiota (Turnbaugh et al., 2009; Verberkmoes et al., 2009).

Recently, the proteins in the feces of two healthy individuals were determined using a community proteomics, or "shotgun metaproteomics" approach (Verberkmoes et al., 2009). Thousands of microbial and host-produced proteins were identified using this technique. A group of approximately 700 equally abundant proteins in the two individuals were suggested to represent the core proteome. This core contained proteins for housekeeping functions, translation, energy production, protein turnover, and carbohydrate metabolism. The proteins present in the core were also representative of common gut bacteria, such as Bacteroides, Bifidobacterium, and Clostridium.

Another key feature of the microbiota that exemplifies coevolution is communication with the host. Some bacteria are able to shape the host to fit their ecological requirements. For example, some bacteria in the gut produce specific effector molecules that function to stimulate 
targeted host functions that benefit the bacteria. Although relatively little is understood about effector molecules secreted by commensal bacteria, the use of effector molecules by pathogenic bacteria has been intensely studied and serves a variety of functions in pathogen establishment. For example, enteropathogenic E. coli inject effector proteins into enterocytes causing actin rearrangement in the host that leads to the formation of a pedestal-like structure thereby allowing intimate microbial-host contact (Dean and Kenny, 2009). Some commensal bacteria secrete effector molecules that stimulate the host to provide a nutrient source, as well as inhibit the inflammatory response (Hooper and Gordon, 2001a, 2001b; Sougioultzis et al., 2003).

The gut environment is also the site of specific intimate metabolic interactions between the host and the microbiota. For example, some members of the gut microbiota have evolved to take advantage of specific host-derived substrates, such as fucose, which is produced by epithelial cells in the gut lining. The best known example of bacterial signaling the host to create a beneficial nutrient environment is demonstrated by Bacteroides thetaiotaomicron. This bacterium signals the host to manufacture fucosylated glycans in place of sialylated glycans because it uses fucose as a main energy source. Segmented filamentous bacteria and a normal microbiota are also able to induce the expression of this glycolipid (Umesaki et al., 1995). The mechanism by which fucosylated glycan production is up-regulated is not yet clear, although the signaling molecule produced by $B$. thetaiotaomicron has been found and termed control of signal production. It has been established that transcription of fucosyltransferase genes are activated by this molecule (Hooper and Gordon, 2001b).

\section{FACTORS AFFECTING THE GUT MICROBIOME}

Major factors affecting microbial number and composition along the length of the intestine 
appear to be age, diet, and host genotype (van der Wielen et al., 2000; Apajalahti et al., 2001; Hill et al., 2005). Comparisons between the zoo animals described previously revealed that diet was the strongest determining factor in shaping microbial composition, where animals were grouped based on whether they were carnivores, herbivores, or omnivores. Gut microbial diversity is generally highest in herbivores, intermediate in omnivores, and lowest in carnivores (Ley et al., 2008). There were, however, intriguing similarities between animal species that indicate the importance of lineage. For example, pandas and bears had relatively similar microbiotas, although their diets are extremely different (Ley et al., 2008). Some of these factors will be discussed in more detail later.

\section{Effect of Diet}

The nutrient requirements for bacteria are highly variable. Therefore, it is not surprising that the composition of the diet is very important in shaping microbial composition. This is particularly true for components of the diet, such as fiber, that escape digestion and absorption by the host in the proximal part of the intestine. The composition of the gut microbiota can change dramatically in response to changes in diet; however, these changes do not always happen quickly. It can take several weeks for activators of microbial degradation enzymes, such as xylanase and cellulose, to adjust to a new diet (Castillo et al., 2006). In the case of omnivores and herbivores, the introduction of plant carbohydrates favors the growth of species that are adapted to the fermentation of dietary fiber. One of the most dramatic changes in microbial composition occurs during the weaning process, where there is a switch from a highly digestible simple liquid diet (milk) to a solid diet that is much more complex and less digestible (Jensen, 1998). Components of human milk contain nonabsorbable oligosaccharides, nucleotides, and gangliosides, which 
affect colonization by bifidobacteria (Kunz and Rudloff, 1993; Balmer et al., 1994; Rueda et al., 1998). It has been shown that bifidobacteria are dominant in feces of breast-fed infants, compared to a more diverse fecal microbiota dominated by Bacteroides spp. in formula-fed infants (Stark and Lee, 1982; Harmsen et al., 2000).

Several studies have examined the impact of obesity on the gut microbiota. The overall diversity of the microbiota is reduced in obese individuals that have an increased food intake (Turnbaugh et al., 2009). There is an intriguing relationship between obesity and composition of the microbiota. By analyzing the microbiota of obese mice $o b / o b$, lean $o b /+$, and wild-type siblings, and their $o b /+$ mothers, Ley et al. (2005) found that $o b / o b$ mice have a reduced abundance of Bacteroidetes and an increase in Firmicutes. The efficiency of fermentation may also be improved in $o b / o b$ mice because of an increased abundance of methanogenic Archaea, which were discussed previously, are responsible for $\mathrm{H}_{2}$ removal (Turnbaugh et al., 2006).

Some specific lifestyle factors can also impact the composition and diversity of the gut microbiota. For example, an anthroposophic lifestyle that entails the consumption of organically produced and fermented foods and the restricted use of antibiotics and vaccinations were correlated with a higher bacterial diversity as compared to a conventional lifestyle or to being raised on a farm (Dicksved et al., 2007). It is, however, difficult to define a causal relationship between diet and microbial composition because many lifestyle factors that coincide with diet also play a role in influencing the microbial composition in the gut. Similar observations have been made in studies examining the effect of diet on cultivable bacteria (Mai, 2004).

\section{The Host Interaction with the Gut Microbiome}

There remains a high variability in the composition of the gut microbiota between individuals, 
even with similar diets and lifestyles. An individual's microbiota is, however, surprisingly stable. The host itself is thus one of the contributing factors in the ecology of the fecal microbiome. It not only creates the abiotic environment, including temperature, $\mathrm{pH}$, and moisture, it also provides nutrients that are utilized by the members of the microbiota and is active in regulating the microbial abundance and composition.

Paneth cells of the SI are known to produce $\alpha$-defensins that protect the proliferative stem cell compartment of the intestinal crypt from colonization (Ayabe et al., 2000). The expression and secretion of RegIII $\gamma$, a bacteriocidal protein effective against only gram-positive bacteria, is induced by host recognition of gram-negative bacteria (Cash et al., 2006). A proteomic study of feces revealed that the third most abundant group of human proteins, after digestive enzymes and structural cell adhesion and cell-cell interaction proteins, were human innate immunity proteins. These included antimicrobial peptides, intellectin, resistin, and others (Verberkmoes et al., 2009). These data therefore provided a glimpse into the protein arsenal that is involved in hostmicrobe interactions in the gut.

An interesting example of the importance of host physiology in shaping the composition of the microbiota was shown in reciprocal transplantations of gut microbiota between mice and zebrafish (Rawls et al., 2006). These authors found that when the microbiota from a mouse was introduced to a germ-free zebrafish, the relative abundance of community members shifted so as to resemble the normal microbial composition of the zebrafish.

Recently, it was shown that the composition of a recipient's fecal microbiota could be altered by fecal transplantation from a donor (Khoruts et al., in press). This particular example involved the case of a woman who suffered from severe diarrhea caused by Clostridium difficileassociated disease. The patient had undergone a series of antibiotic treatments, all of which were 
unsuccessful. As a last resort the attending physician prescribed a fecal transplantation from a healthy donor. Interestingly, not only did this cure the disease, but the patient adopted the fecal microbial composition of the donor, at least for several weeks. These results indicate that the host programmed microbiome may be altered in some cases, at least temporarily, and suggest a therapy for severe cases of $C$. difficile-associated disease.

Studies comparing the microbial composition of twins, related individuals, and unrelated individuals indicate an important role of host genotype in shaping microbial composition. Twins living in different environments share a more similar microbiota than do twins and their spouses who share the same environment and diet (Zoetendal et al., 2001). A more recent study that examined the gut microbiota of obese and lean twins and their mothers, using clone libraries and pyrosequencing, revealed that related individuals had more bacterial species in common and a more similar bacterial community structure than unrelated individuals, regardless of obesity status (Turnbaugh et al., 2009). We have performed extensive studies on a Swedish twin cohort that include healthy individuals and individuals with different inflammatory bowel diseases (see more detail later). Our initial T-RFLP data revealed a high degree of similarity in the gut microbiota of identical twins, even when they lived apart for decades (Dicksved et al., 2008). More recently, 454 pyrosequencing data revealed that, although the healthy twins shared some degree of similarity at an OTU/species level, the similarity was much more apparent at the genus level (Willing et al., unpublished data).

\section{Impact of Disease}

There is increasing evidence linking the composition of the gut microbiota to the health of the host, both positively and negatively. Some examples of diseases where the gut microbiota is 
implicated to have a role, although still largely undefined, include inflammatory bowel diseases (IBDs) such as irritable bowel syndrome, Crohn's disease (CD), ulcerative colitis, and colon cancer. In this chapter we primarily discuss $\mathrm{CD}$ because of the large number of recent reports that have focused on the correlation of the gut microbiota to this particular disease.

Different molecular fingerprinting techniques, including T-RFLP (Dicksved et al., 2008; Willing et al., 2009a), TGGE (Seksik et al., 2005), qPCR (Willing et al., 2009a), and 454 pyrosequencing (Willing et al., unpublished data), have revealed that the gut microbiota is different in individuals with CD compared to healthy individuals. This altered gut microbiota has been referred to as a state of "dysbiosis" (Seksik et al., 2005; Tamboli et al., 2004). The theory of dysbiosis is that there is a breakdown in the balance between species of protective versus harmful intestinal bacteria that is either a cause, or a consequence, of disease (Tamboli et al., 2004).

Recent findings have honed in on specific members of the gut microbiota that are more or less prevalent in individuals with CD. For example, a T-RFLP study of identical twins that were discordant for $\mathrm{CD}$ found that there were differences in relative amounts of some Bacteroides species in the twins with CD, compared to healthy twins (Dicksved et al., 2008). Individuals with $\mathrm{CD}$ in the ileum also had a lower bacterial diversity in the mucosal lining of the intestine, compared to those with disease localized in the colon (Willing et al., 2009a). Several studies have implicated E. coli (Darfeuille-Michaud et al., 2004; Baumgart et al., 2007; Willing et al., 2009a) or Mycobacterium paratuberculosis (Naser et al., 2004) as potential virulent species that may have a specific role in the pathogenesis of $\mathrm{CD}$, but these microbes remain to be confirmed. One striking example of dysbiosis is the dramatic reduction in abundance of some members of the Clostridium leptum group (Cluster IV), such as Faecalibacterium prausnitzii, in fecal 
samples and biopsies of individuals with CD (Swidsinski et al., 2008; Willing et al., 2009a). F. prausnitzii is considered to be a beneficial member of the commensal microbiota because of its ability to produce butyrate and provide therapeutic properties in a mouse IBD model (Sokol et al., 2008). One hypothesis is that a reduction in F. prausnitzii would result in a reduced amount of butyrate that could trigger gut inflammation, or even induce the expression of antimicrobial peptides, thus allowing pathogenic $E$. coli to proliferate. Recent 454 pyrosequencing data (Willing et al., unpublished data) have revealed that the situation is even more complex and that several additional bacteria differ in individuals with different IBD phenotypes. These differentiating populations might serve as diagnostic targets of IBD in the future and obviate the current need for invasive endoscopic tests.

\section{Methods to Alter the Microbiota}

In animal production, the search for a means to manipulate the microbiota to promote growth and prevent disease has been a major focus of animal nutritionists. Antibiotics have been used to regulate the GI microbiota of livestock for the last half of the 20th century. The development of antibiotic resistance and "superbugs," however, has resulted in a ban of in-feed antibiotics in the European Union. The growing awareness of the importance of the microbiota in health and disease has also resulted in an increased interest in manipulating the microbiota in human nutrition. Alternative strategies to regulate the microbial population that have become commonplace include the use of prebiotics and probiotics as supplements. Prebiotics are dietary additives that are directed at promoting health through their effects on the microbiota (Gibson and Roberfroid, 1995), whereas a probiotic is defined as a live microbial feed supplement that beneficially affects the host by improving its intestinal balance (Fuller, 1989). The majority of 
probiotic organisms used are lactic acid bacteria, which include a variety of lactobacilli, enterococci, and bifidobacteria. Other probiotics include bacteria within the genus Bacillus and yeasts such as Saccharomyce cerevisiae. The probiotic mode of action is generally accredited to competitive exclusion of pathogens and strengthening of the mucosal barrier (Servin, 2004; Saxelin et al., 2005). In contrast, prebiotics are largely concentrated on the use of indigestible carbohydrates that can be utilized by bacteria in the large bowel. The effect of these carbohydrates on the microbiota is dependent on how available they are to bacterial fermentation, which is dependent on water solubility and the degree of polymerization and lignification. The prebiotics inulin and fructooligosaccharides have been shown to stimulate the growth of beneficial gut bacteria, such as bifidobacteria and lactobacilli (Van Loo, 2004).

\section{MICROBIAL METABOLISM IN THE GUT}

The different microbes residing in the gut carry out specific metabolic processes that can directly or indirectly impact the host. Metabolites produced by gut microbiota can be transferred across the epithelial barrier and reach systemic sites of the host. This was evident, for example, when comparing the plasma metabolic profiles of germ-free and conventional mice. Numerous circulating metabolites were only present when the mice were colonized by microorganisms and there were significant differences in the abundance of several metabolites in germ-free and conventional mice (Claus et al., 2008; Wikoff et al., 2009). Claus et al. (2008) found that the microbiome has an impact on the metabolism of bile acids and kidney homeostasis. These data confirm that microbes modulate the expression of metabolites both locally in the gut and in other body sites.

One of the goals of current research is to identify metabolites, including those of 
microbial origin, that are diagnostic biomarkers of health or disease of the host. This goal may soon be realized because the availability of new and advanced technologies that produce detailed information about the metabolic composition in human samples, including feces, urine, and blood. These technologies include gas chromatography-mass spectrometry (GC-MS), ${ }^{1} \mathrm{H}$ nuclear magnetic resonance (NMR) spectroscopy, and ion cyclotron resonance Fourier transform mass spectrometry (ICR-FT/MS). These methods have recently been used to determine hundreds to thousands of metabolites in human samples, collectively referred to as the "metabolome" and the field of "metabolomics" or "metabonomics" (Nicholson et al., 2005; Jansson et al., 2009).

\section{Beneficial Metabolites}

In return for a hospitable environment and provision of nutrients, the microbiota provide the host with major services. The cumulative microbiota has a vast capacity to mediate a diverse set of beneficial roles for the host (Marchesi and Shanahan, 2007). These roles include synthesis of vitamins, degradation of xenobiotics, metabolism of bile and host hormones (Hooper et al., 1998), immune development, and the competitive exclusion of pathogens.

One of the most important roles that the microbiota provides is the provision of energy for the host's colonic epithelium. The energy provided is primarily in the form of short chain fatty acids (SCFAs) that are produced by bacterial fermentation of undigested carbohydrates and fiber (Karaki et al., 2006). Accordingly, SCFA production is highly affected by diet. Depending on the animal species and the nature of the diet, SCFA can make up as much as $70 \%$ of the energy that the host derives from the diet and, of these, butyrate is the preferred energy source for colonocytes (Bergman, 1990). Interestingly, different types of SCFAs are produced in the gut of bottle- versus breast-fed infants. The SCFAs produced by the gut microbiota in formula-fed 
babies have less lactic acid and more propionic acid than in breast-fed babies (Edwards et al., 1994). Not all populations of bacteria are equal in their ability to liberate energy from the diet. A reduction in Bacteroidetes and an increase in Firmicutes, for example, has been shown to increase SCFA production resulting in increased energy for the host and, in some cases, contribute to obesity (Turnbaugh et al., 2006).

The fermentation of undigested dietary components results in the production of an extensive combination of metabolites, many of which remain to be characterized. Studies comparing the blood metabolites of germ-free to conventional animals indicate that the metabolites produced by bacteria can have systemic effects (Wikoff et al., 2009). Modifying the composition of the microbiota using nutritional changes can modulate host lipid, carbohydrate, and amino acid metabolism (Martin et al., 2009). These effects may improve health because, for

example, some bacteria cause reduced plasma lipoproteins (Martin et al., 2009). The composition of the microbiota has been shown to correlate with components of the fecal metabolome as well as metabolites found in the urine (Marchesi et al., 2007; Jansson et al., 2009). The variation in abundance of Faecalibacterium prausnitzii has been associated with the modulation of at least eight urinary metabolites of diverse structure (Li et al., 2008).

\section{Biomarkers of Disease}

Shifts in the gut microbiota and their metabolites have been correlated to several diseases, including diabetes, obesity, and IBD. Because fecal extracts of patients with IBD have reduced levels of butyrate, acetate, methylamine, and trimethylamine, changes in metabolite profiles associated with changes in microbial populations likely play an important role in intestinal health (Marchesi et al., 2007). Using ICR-FT/MS, we recently found that the situation is even more 
complex - thousands of metabolites differentiated individuals with different CD phenotypes and healthy individuals (Jansson et al., 2009). Pathways with differentiating metabolites include those for metabolism of amino acids, fatty acids, bile acids, and arachidonic acid. The mass spectrum corresponding to glycocholic acid in the bile acid biosynthesis pathway was more prevalent in individuals with $\mathrm{CD}$ than in healthy individuals. Increased bile in the feces may be one of the causes leading to symptoms associated with inflammation in $\mathrm{CD}$. This example illustrates the important contribution of the metabolic processes carried out by the gut microbiota on human health. In addition to the mass spectra that could be identified using this large metabolic survey, there were several hundred that could not be identified because of their absence in current metabolic databases. Therefore, there remains a tremendous amount to be discovered about the metabolic processes occurring in the gut.

\section{Toxic Metabolites}

The intestinal microbiota can also produce a variety of metabolites such as $\mathrm{NH}_{3}, \mathrm{H}_{2} \mathrm{~S}$, and deconjugated bile and phenolics, which are toxic to the host both locally in the small intestine and systemically. The deamination of amino acids by microorganisms leads to the production of ammonia, a toxic metabolite that has been considered in the etiology of IBD. This was hypothesized because in vitro studies have shown that the microbiota of IBD patients produce more ammonia compared to those from healthy individuals (Van Nuenen et al., 2004). Perfusion of ammonia into the rat colon showed that the life span of colon cells is shortened by ammonia and it also induces proliferation of mucosa (Lin and Visek, 1991). Because ammonia is used as a preferential nitrogen source by carbohydrate-fermenting bacteria (Bryant, 1974), ammonia concentration in the feces can be reduced by feeding fermentable carbohydrates (Awati et al., 
2006).

Hydrogen sulfide $\left(\mathrm{H}_{2} \mathrm{~S}\right)$ is produced by bacteria as a result of the fermentation of sulfurcontaining amino acids and other dietary and host-derived sulfur sources, including sulfurcontaining mucins (Florin et al., 1991; Magee et al., 2000). $\mathrm{H}_{2} \mathrm{~S}$ reduces overall metabolic activity of the intestinal epithelial cells leading to a reduction in the oxidation of glutamine, butyrate, and acetate (Leschelle et al., 2005). This reduction in overall metabolic activity and slow down of all cell cycle phases leads to a reduction in mitotic activity.

Deconjugation of bile may affect fat digestion and fat soluble vitamin absorption (Knarreborg et al., 2002a) and production of lithocholic acid may be toxic to enterocytes (Knarreborg et al., 2002b; Wanitschke and Ammon, 1978). Lactobacilli are responsible for the majority of bile salt hydrolysis, although Bacteroides, Bifidobacterium, and Clostridium spp. all have bile salt hydrolase activity (Gaskins, 2001). Changes in the microbiota have been correlated to increased dehydroxylation of cholic acid, a main bile acid, to deoxycholic acid (Kitahara et al., 2004). Increased levels of bile acid metabolites have also been detected in Crohn's patients, which may play a role in disease progression (Jansson et al., 2009).

Microbial production of phenolics can also lead to the production of toxic metabolites, although this is highly variable between individuals, most likely because the variation in the composition of gut microbiota (Van Nuenen et al., 2004). For example, metabolism of tyrosine leads to the production of several toxic compounds including $\rho$-cresol (Bakke and Midtvedt, 1970). The $\rho$-cresol is absorbed and conjugated to $\rho$-cresylsulphate, which has been shown to increase the percentage of leukocytes displaying oxidative burst activity (Schauser and Larsson, 2005). It has been suggested that microbiologically produced phenolics reduce growth in weanling pigs and antibiotic treatment reduces urinary and fecal excretion of aromatic 
compounds (Yokoyama et al., 1982). Bacteroides, Lactobacillus, Clostridium, and Bifidobacterium species strains are major producers of phenolic compounds from aromatic amino acids (Macfarlane and Macfarlane, 1995).

\section{Bioactive Metabolites}

Bacteria along with digestive enzymes break down dietary proteins, converting them into peptides, some of which are bioactive. The extent of in vivo production of bioactive peptides by luminal bacteria has yet to be directly studied. It is known, however, that bioactive peptides have diverse effects on the host, ranging from local effects in the intestine (such as mucin production) to systemic effects (such as reduced blood pressure). Many of the effects of bioactive peptides are receptor-mediated and, although some of those receptors have been identified, there still remains much to be defined.

$\beta$-casomorphin-7, a bioactive peptide that is a product of milk fermentation, causes a dramatic increase in mucin production in rat intestinal cells (Trompette et al., 2003). This bioactive peptide acts directly on the intestinal epithelium by activation of specific receptors (Zoghbi et al., 2006). This interaction likely leads to improved intestinal protection and may have implications for improved intestinal health.

Some probiotic microbes, such as Lactobacillus casei (Thoreux et al., 1998) also produce bioactive metabolites that specifically interact with the host epithelial cells in the intestine. $L$. johnsonnii appears to produce a metabolite that lowers blood pressure via a histaminergic receptor present in the intestinal epithelium (Tanida et al., 2005). These different metabolites may, at least in part, be responsible for some of the beneficial properties of ingestion of probiotic bacteria. 


\section{Immune Development and Protection}

The effects of the microbiota on the mucosal immune system are vast, ranging from the enhancement of barrier integrity by stimulating the expression of tight junction proteins (Danielsen et al., 2007), to the balancing of the T-helper (Th) cell population (Mazmanian et al., 2005). For example, B. thetaiotaomicron colonization leads to differential transcription of host genes responsible for nutrient absorption, mucosal barrier fortification, xenobiotic metabolism, angiogenesis, and intestinal maturation (Hooper et al., 2001).

A healthy microbiota is important not only in the development of immunity, but also in maintained protection against specific pathogens, such as Salmonella. A normal mouse microbiota confers resistance to Salmonella-induced gastroenteritis and shifting of the normal microbiota creates increased susceptibility to Salmonella (Sekirov et al., 2008). This function is not simply a matter of total bacterial abundance. The type of bacteria present is important because disruption of the composition of the microbiota without a reduction in total levels led to increased susceptibility to enteric infection by Salmonella and other enteric pathogens (Sekirov et al., 2008). The mechanistic explanation for this is yet to be defined; however, it is expected that it is either the result of competitive exclusion by commensal bacteria or the result of immune regulation by other bacteria.

In a separate study, Brandl et al. (2008) reported that the normal microbiota seemingly inadvertently prevented infection by enterococci by causing the host to secrete the antimicrobial peptide, RegIII $\gamma$. When the normal microbiota was removed by use of antibiotics, the expression of this peptide dropped, and the host became susceptible to infection. However, protection could be maintained by adding bacterial lipopolysaccharide (LPS) during the course of antibiotic 
treatment, indicating the importance of maintaining appropriate immune stimulation. The ability of the microbiota to regulate the host immune system is extremely important because, if the homeostasis established between the host and microbiota is disrupted, overt inflammation can occur leading to IBD as discussed previously.

\section{MICROBIAL INTERACTIONS}

\section{Syntrophy}

Bacterial dependency on co-colonizers is exemplified by cross-feeding. Synergism can be exemplified by the relationship between Eubacterium hallii and Anaerostipes caccae. These organisms cannot grow separately on starch; however, they are able to do so when co-cultured with Bifidobacterium adolescentis. B. adolescentis provides these organisms with lactate to grow and to produce butyrate. A second mechanism is demonstrated by the inability of Roseburia sp. A2-183 to grow on fructooligosaccharides (FOS). When co-cultured with B. adolescentis, Roseburia is able to utilize the partially degraded FOS (Belenguer et al., 2006). The syntrophic interactions between bacteria in the metabolism of carbohydrates are shown in Fig. 4.

The removal of reducing units $\left(\mathrm{H}_{2}\right)$ is very important for overall microbial community dynamics and is a key process in many syntrophic interactions. As mentioned previously, about $30 \%$ to $50 \%$ of individuals in the Western population dispose of hydrogen via methanogenesis. These individuals can be identified using a simple breath test for methane production. The remaining human population use different $\mathrm{H}_{2}$ disposal routes, via sulfate reduction or reductive acetogenesis. Gut metagenome studies of two American individuals (Gill et al., 2006) found that the genes involved in methanogenesis were abundant, suggesting that methanogenesis in their gut environments occurred via the $\mathrm{H}_{2}$ disposal route. By contrast, the metagenomes of Japanese 
individuals (Kurokawa et al., 2007) and the proteomes of Swedish individuals (Verberkmoes et al., 2009) contained genes and proteins, respectively, that were typical of the acetogenic $\mathrm{H}_{2}$ disposal route.

In most animal species, $\mathrm{H}_{2}$-utilizing organisms are dominated by methanogens (Morvan et al., 1996). Other known $\mathrm{H}_{2}$-utilizing organisms found in the gut include homoacetogens and sulfate-reducing bacteria (Christl et al., 1992; Strocchi et al., 1994). In an experiment where $M$. smithii and B. thetaiotaomicron were used to inoculate mice alone or together, co-colonization resulted in a 100- to 1,000-fold increase in the abundance of both organisms. This increased colonization indicated that the methanogen was more successful with a source of $\mathrm{H}_{2}$ and that the accumulation of $\mathrm{H}_{2}$ in the environment was inhibiting the growth of B. thetaiotaomicron. Because there is a great deal of competition for $\mathrm{H}_{2}$ in the gut between acetogens, sulfate-reducing bacteria, and methanogens, it seems likely that in a normal gut environment there is never a buildup of $\mathrm{H}_{2}$ to inhibit bacterial NADH dehydrogenases.

\section{Bacteriocins}

One bacterial competitive tactic is to produce bacteriocins that kill neighboring bacterial cells. This mechanism, however, does not always result in the expected outcome so that it remains competitive. For example, one might expect that, in a system where there is a bacteriocin producing bacterium and one susceptible to that bacteriocin, the producing strain would have a growth advantage. In a simple system this would likely be the case, but, as described previously, the gut microbiota is extremely complex. The complexity of this situation was demonstrated by introducing three E. coli strains that included an isolate that produced colicins (narrow-spectrum antibiotics produced by and active against E. coli), one that was susceptible to colicins, and 
another that was resistant to colicins (Kirkup and Riley, 2004). The result of this experiment was a bacterial game of "rock-paper-scissors," where each strain took its turn at being the dominant E. coli found in the mouse gut.

\section{Interacting Through the Host}

The host also plays an important role in the competition between bacteria. $B$. thetaiotamicron (gram-negative) stimulates host expression of genes responsible for antimicrobial activity targeting gram-positive bacteria, whereas Bifidobacterium longum (gram-positive) suppresses the expression of these same genes (Sonnenburg et al., 2006). Another interaction through the host immune system is indicated by a mechanism where the commensal microbiota protects the host from Enterococcus infection by inducing host expression of a c-type lectin that kills grampositive bacteria (Brandl et al., 2008).

\section{Model Systems}

There are two in vivo model systems that have been employed to study microbial interactions in the intestine. In the first system, a germ-free (or gnotobiotic) animal is used as a host for a defined bacterial population or community. An alternate approach is to remove individual components of the indigenous microbiota and to observe losses of function or changes in response microbial loss. A number of attempts have also been made to model the GI microbiota in vivo (Kovatcheva-Datchary et al., 2009), but this is challenged by the inability to accurately mimic the contributions of the host.

A recent study demonstrated the complexity of the relationships in the GI ecosystem by creating a model system made up of single representatives from each of the two main phyla 
present in the human GI tract (Mahowald et al., 2009): Eubacterium rectale, a prominent member of Firmicutes, and B. thetaiotaomicron, a common and well-characterized organism of Bacteroidetes. These two bacteria were then introduced into germ-free mice alone (monoassociation) and together (di-association). Transcriptional profiling of both bacteria and the host revealed that these two bacteria changed their behavior depending on whether they are colonizing the host alone or with other bacteria. Host response to these bacteria was not simply additive and revealed that the interactions between bacteria resulted in amplified and modified microbial-host interactions (Willing and Finlay, 2009) (Fig. 5). Co-colonization with E. rectale caused B. thetaiotaomicron to increase the expression of glycan-degrading enzymes, presumably as a consequence of competition for dietary carbohydrate. As a result of the lack of nutrients, $B$. thetaiotaomicron also began sending signals to the host to produce glycans that it, but not $E$. rectale, could utilize. Based on genome analysis of B. thetaiotaomicron and other sequenced Bacteroidetes, these bacteria appear to have a surplus of glycan degrading enzymes compared to members of Firmicutes. The ability of B. thetaiotaomicron to utilize host-drived glycans in the face of competition by Firmicutes may therefore be a common adaptation used by Bacteroidetes to remain competitive. Although B. thetaiotaomicron increased its ability to degrade carbohydrate in the face of competition, E. rectale decreased expression of glycan-degrading enzymes and increased expression of a number of amino acid and peptide transporters. Results of this study also demonstrated that there were synergistic interactions between these two bacteria. Although E. rectale was able to produce butyrate from the metabolism of carbohydrates, this bacterium was able to produce much more butyrate when co-colonized with $B$. thetaiotaomicron. Moreover, butyrate was more efficiently produced in a situation where acetyl-CoA produced by B. thetaiotaomicron was utilized and converted to butyrate by E. rectale. As discussed 
previously, butyrate regulates many host functions. Therefore, the increased production of butyrate resulted in greater host responses to colonization. Although this model gave some new insights into the complex ecology of the gut microbiota, it is yet unclear whether the interactions observed between E. rectale and B. thetaiotaomicron are representative of common interactions between Bacteroidetes and Firmicutes.

\section{CONCLUSION}

Although we are gaining increasing appreciation of the important role that the gut microbiota play in health and disease, we are also becoming aware of the complexity of the gut ecosystem. The advent of "omics" tools has enabled us to obtain vast amounts of data about species, genes, proteins, and metabolites in the gut. However, we are lagging behind in the development of bioinformatics and biostatistics tools that enable us to mine these enormous data sets and to perform correlations between them. It is currently a massive puzzle to determine which microbial species and/or processes are essential for normal gut function, for different disease states, and other physiological conditions, such as obesity. These puzzles are further confounded by the large variation in microbial species composition among individuals that makes generalizations difficult. The study of genetically matched twins and defined model systems are examples of approaches that have promise to help define diagnostic targets and disease biomarkers. Eventually, we will need to combine information gleaned from molecular approaches with detailed biochemical and physiological studies of the effects of specific microbes, proteins, and metabolites on health (e.g., in a gnotobiotic animal model) to fulfill the requirements of Koch's postulates. Current evidence also suggests that these simple models will need to be modified to take into account interactions that occur between microbes and the host in the gut. The hope for 
the future is that we will be able to design diet plans and drugs that optimize beneficial microbial functions in the gut and that these will result in health benefits to individuals. 


\section{REFERENCES}

Andersson, A. F., M. Lindberg, H. Jakobsson, F. Backhed, P. Nyren, and L Engstrand. 2008. Comparative analysis of human gut microbiota by barcoded pyrosequencing. PLoS One 3:e2836.

Apajalahti, J. H. A., A. Kettunen, M. R. Bedford, and W E. Holben. 2001. Percent G+C profiling accurately reveals diet-related differences in the gastrointestinal microbial community of broiler chickens. Appl. Environ. Microbiol. 67:5656-5667.

Awati, A., B. Williams, M. Bosch, W. Gerrits, and M. Verstegen. 2006. Effect of inclusion of fermentable carbohydrates in the diet on fermentation end-product profile in feces of weanling piglets. J. Anim. Sci. 84:2133-2140.

Ayabe, T., D. P. Satchell, C. L. Wilson, W. C. Parks, M. E. Selsted, and A. J. Ouellette. 2000. Secretion of microbicidal alpha-defensins by intestinal Paneth cells in response to bacteria. Nature Immunol. 1:113-118.

Backhed, F., R. E. Ley, J. L. Sonnenburg, D. A. Peterson, and J. I. Gordon. 2005. Hostbacterial mutualism in the human intestine. Science 307:1915-1920.

Bakke, O. M., and T. Midtvedt. 1970. Influence of germ-free status on excretion of simple phenols of possible significance in tumour promotion. Experientia 26:519.

Balmer, S., L. Hanvey, and B. Wharton. 1994. Diet and fecal flora in the newborn Nucleotides. Arch. Dis. Child. 70:F137-F140.

Baumgart, M., B. Dogan, M. Rishniw, G. Weitzman, B. Bosworth, R. Yantiss, R. H. Orsi, M. Wiedmann, P. McDonough, S. G. Kim, D. Berg, Y. Schukken, E. Scherl, and K. W. Simpson. 2007. Culture independent analysis of ileal mucosa reveals a selective increase in invasive Escherichia coli of novel phylogeny relative to depletion of 
Clostridiales in Crohn's disease involving the ileum. ISME J. 1:403-418.

Belenguer, A., S. H. Duncan, A.G. Calder, G. Holtrop, P. Louis, G. E. Lobley, and H. J.

Flint. 2006. Two routes of metabolic cross-feeding between Bifidobacterium adolescentis and butyrate-producing anaerobes from the human gut. Appl. Environ. Microbiol. 72:3593-3599.

Berg, R. D. 1996. The indigenous gastrointestinal microflora. Trends Microbiol. 4:430-435.

Bergman, E. N. 1990. Energy contributions of volatile fatty acids from the gastrointestinal tract in various species. Physiol. Rev. 70:567-590.

Brandl, K., G. Plitas, C. N. Mihu, C. Ubeda, T. Jia, M. Fleisher, B. Schnabl, R. P. DeMatteo, and E. G. Pamer. 2008. Vancomycin-resistant enterococci exploit antibioticinduced innate immune deficits. Nature 455:804-U808.

Bryant, M. P. 1974. Nutritional features and ecology of predominant anaerobic bacteria of intestinal-tract. Am. J. Clin. Nutr. 27:1313-1319.

Cash, H. L., C. V. Whitham, C. L. Behrendt, and L. V. Hooper. 2006. Symbiotic bacteria direct expression of an intestinal bactericidal lectin. Science 313:1126-1130.

Castillo, M., S. M. Martin-Orue, M. Roca, E. G. Manzanilla, I. Badiola, J. F. Perez, and J. Gasa. 2006. The response of gastrointestinal microbiota to avilamycin, butyrate, and plant extracts in early-weaned pigs. J. Anim. Sci. 84:2725-2734.

Christl, S. U., P. R. Murgatroyd, G. R. Gibson, and J. H. Cummings. 1992. Production, metabolism, and excretion of hydrogen in the large-intestine. Gastroenterology 102:1269-1277.

Claus, S. P., T. M. Tsang, Y. L. Wang, O. Cloarec, E. Skordi, F. P. Martin, S. Rezzi, A. Ross, S. Kochhar, E. Holmes, and J. K. Nicholson. 2008. Systemic 
multicompartmental effects of the gut microbiome on mouse metabolic phenotypes. Mol. Syst. Biol. 4:219.

Cummings, J. H., and G. T. Macfarlane. 1991. The control and consequences of bacterial fermentation in the human colon. J. Appl. Bacteriol. 70:443-459.

Danielsen, M., H. Hornshoj, R. H. Siggers, B. B. Jensen, A. G. van Kessel, and E. Bendixen. 2007. Effects of bacterial colonization on the porcine intestinal proteome. J. Proteome Res. 6:2596-2604.

Darfeuille-Michaud, A., J. Boudeau, P. Bulois, C. Neut, A. L. Glasser, N. Barnich, M. A. Bringer, A. Swidsinski, L. Beaugerie, and J. F. Colombel. 2004. High prevalence of adherent-invasive Escherichia coli associated with ileal mucosa in Crohn's disease. Gastroenterology 127:412-421.

Dean, P., and B. Kenny. 2009. The effector repertoire of enteropathogenic E. coli: ganging up on the host cell. Curr. Opin. Microbiol. 12:101-109.

Dethlefsen, L., S. Huse, M. L. Sogin, and D. A. Relman. 2008. The pervasive effects of an antibiotic on the human gut microbiota, as revealed by deep $16 \mathrm{~S}$ rRNA sequencing. PLoS Biol. 6:2383-2400.

Dicksved, J., H. Floistrup, A. Bergstrom, M. Rosenquist, G. Pershagen, A. Scheynius, S. Roos, J. S. Alm, L. Engstrand, C. Braun-Fahrlander, E. von Mutius, and J. K. Jansson. 2007. Molecular fingerprinting of the fecal microbiota of children raised according to different lifestyles. Appl. Environ. Microbiol. 73:2284-2289.

Dicksved, J., J. Halfvarson, M. Rosenquist, G. Jarnerot, C. Tysk, J. Apajalahti, L. Engstrand, and J. K. Jansson. 2008. Molecular analysis of the gut microbiota of identical twins with Crohn's disease. ISME J. 2:716-727. 
Dixit, S., D. Gordon, X. Wu, T. Chapman, K. Kailasapathy, and J. Chin. 2004. Diversity analysis of commensal porcine Escherichia coli - associations between genotypes and habitat in the porcine gastrointestinal tract. Microbiology 150:1735-1740.

\section{Dossopoulos, T., C. Frongakis, M. Cruz-Correa, M. V. Talor, C. L. Burek, L. Datta, F.} Nouvet, T. M. Bayless, and S. R. Brant. 2007. Antibodies to Saccharomyces cerevisiae in Crohn's disease: higher titers are associated with a greater frequency of mutant NOD2/CARD15 alleles and with a higher probability of complicated disease. Inflamm. Bowel Dis. 13:143-151.

Dumonceaux, T. J., J. E. Hill, S. M. Hemmingsen, and A. G. Van Kessel. 2006. Characterization of intestinal microbiota and response to dietary virginiamycin supplementation in the broiler chicken. Appl. Environ. Microbiol. 72:2815-2823.

Eckburg, P. B., E. M. Bik, C. N. Bernstein, E. Purdom, L. Dethlefsen, M. Sargent, S. R. Gill, K. E. Nelson, and D. A. Relman. 2005. Diversity of the human intestinal microbial flora. Science 308:1635-1638.

Edwards, C., A. Parrett, S. Balmer, and B. Wharton. 1994. Fecal short-chain fatty-acids in breast-fed and formula-fed babies. Acta Paediatr. 83:459-462.

Florin, T., G. Neale, G. R. Gibson, S. U. Christl, and J. H. Cummings. 1991. Metabolism of dietary sulfate - absorption and excretion in humans. Gut 32:766-773.

Frece, J., B. Kos, J. Beganovic, S. Vukovic, and J. Suskovic. 2005. In vivo testing of functional properties of three selected probiotic strains. World J. Microb. Biotechnol. 21:1401-1408.

Fuller, R. 1989. Probiotics in man and animals. J. Appl. Bacteriol. 66:365-378.

Gaskins, H. R. 2001. Intestinal bacteria and their influence on swine growth, p. 1009. In A. J. 
Lewis and L. L. Southern (ed.), Swine Nutrition. CRC Press, Boca Raton, FL.

Gibson, G. R., and M. B. Roberfroid. 1995. Dietary modulation of the human colonic microbiota: introducing the concept of prebiotics. J. Nutr. 125:1401-1412.

Gill, S. R., M. Pop, R. T. DeBoy, P. B. Eckburg, P. J. Turnbaugh, B. S. Samuel, J. I. Gordon, D. A. Relman, C. M. Fraser-Liggett, and K. E. Nelson. 2006. Metagenomic analysis of the human distal gut microbiome. Science 312:1355-1359.

Gronlund, M. M., O. P. Lehtonen, E. Eerola, and P. Kero. 1999. Fecal microflora in healthy infants born by different methods of delivery: permanent changes in intestinal flora after cesarean delivery. J. Pediatr. Gastroenterol. Nutr. 28:19-25.

Harmsen, H. J., A. C. Wildeboer-Veloo, G. C. Raangs, A. A. Wagendorp, N. Klijn, J. G. Bindels, and G. W. Welling. 2000. Analysis of intestinal flora development in breast-fed and formula-fed infants by using molecular identification and detection methods. $J$. Pediatr. Gastroenterol. Nutr. 30:61-67.

Hernandez, J. D., P. T. Scott, R. W. Shephard, and R. A. Al Jassim. 2008. The characterization of lactic acid producing bacteria from the rumen of dairy cattle grazing on improved pasture supplemented with wheat and barley grain. J. Appl. Microbiol. 104:1754-1763.

Hill, J. E., R. P. Seipp, M. Betts, L. Hawkins, A. G. V. Kessel, W. L. Crosby, and S. M. Hemmingsen. 2002. Extensive profiling of a complex microbial community by highthroughput sequencing. Appl. Environ. Microb. 68:3055-3066.

Hill, J. E., S. L. Penny, K. G. Crowell, S. H. Goh, and S. M. Hemmingsen. 2004. cpnDB: a chaperonin sequence database. Genome Res. 14:1669-1675.

Hill, J. E., S. M. Hemmingsen, B. G. Goldade, T. J. Dumonceaux, J. Klassen, R. T. Zijlstra, 
S. H. Goh, and A. G. Van Kessel. 2005. Comparison of ileum microflora of pigs fed corn-, wheat-, or barley-based diets by chaperonin-60 sequencing and quantitative PCR. Appl. Environ. Microbiol. 71:867--875.

Hook, S. E., K. S. Northwood, A. D. Wright, and B. W. McBride. 2009. Long-term monensin supplementation does not significantly affect the quantity and diversity of methanogens in the rumen of the lactating dairy cow. Appl. Environ. Microb. 75:374-380.

Hooper, L. 2004. Bacterial contributions to mammalian gut development. Trends Microbiol. 12:129-134.

Hooper, L., and J. Gordon. 2001a. Commensal host-bacterial relationships in the gut. Science 292:1115-1118.

Hooper, L., and J. Gordon. 2001b. Glycans as legislators of host-microbial interactions: spanning the spectrum from symbiosis to pathogenicity. Glycobiology 11:1R-10R.

Hooper, L., L. Bry, P. G. Falk, and J. I. Gordon. 1998. Host-microbial symbiosis in the mammalian intestine: exploring an internal ecosystem. Bioessays 20:336-343.

Hooper, L., M. Wong, A. Thelin, L. Hansson, P. Falk, and J. Gordon. 2001. Molecular analysis of commensal host-microbial relations hips in the intestine. Science 291:881884.

Janczyk, P., R. Pieper, H. Smidt, and W. B. Souffrant. 2007. Changes in the diversity of pig ileal lactobacilli around weaning determined by means of 16S rRNA gene amplification and denaturing gradient gel electrophoresis. FEMS Microbiol. Ecol. 61:132-140.

Jansson, J., B. Willing, M. Lucio, A. Fekete, J. Dicksved, J. Halfvarson, C. Tysk, and P. Schmitt-Kopplin. 2009. Metabolomics reveals metabolic biomarkers of Crohn's disease. PLoS One 4:e6386. 
Jensen, B. B. 1998. The impact of feed additives on the microbial ecology of the gut in young pigs. J. Anim. Feed Sci. 7:45-64.

Jernberg, C., A. Sullivan, C. Edlund, and J. K. Jansson. 2005. Monitoring of antibioticinduced alterations in the human intestinal microflora and detection of probiotic strains by use of terminal restriction fragment length polymorphism. Appl. Environ. Microbiol. 71:501-506.

Jernberg, C., S. Lofmark, C. Edlund, and J. K. Jansson. 2007. Long-term ecological impacts of antibiotic administration on the human intestinal microbiota. ISME J. 1:56-66.

Johansson, M. E. V., M. Phillipson, J. Petersson, A. Velcich, L. Holm, and G. C. Hansson. 2008. The inner of the two Muc2 mucin-dependent mucus layers in colon is devoid of bacteria. Proc. Natl. Acad. Sci. USA 105:15064-15069.

Karaki, S., R. Mitsui, H. Hayashi, I. Kato, H. Sugiya, T. Iwanaga, J. B. Furness, and A. Kuwahara. 2006. Short-chain fatty acid receptor, GPR43, is expressed by enteroendocrine cells and mucosal mast cells in rat intestine. Cell Tissue Res. 324:353360.

Kirkup, B. C., and M. A. Riley. 2004. Antibiotic-mediated antagonism leads to a bacterial game of rock-paper-scissors in vivo. Nature 428:412-414.

Kitahara, M., S. Sakata, M. Sakamoto, and Y. Benno. 2004. Comparison among fecal secondary bile acid levels, fecal microbiota and Clostridium scindens cell numbers in Japanese. Microbiol. Immunol. 48:367-375.

Knarreborg, A., R. M. Engberg, S. K. Jensen, and B. B. Jensen. 2002a. Quantitative determination of bile salt hydrolase activity in bacteria isolated from the small intestine of chickens. Appl. Environ. Microbiol. 68:6425-6428. 
Knarreborg, A., M. A. Simon, R. M. Engberg, B. B. Jensen, and G. W. Tannock. 2002 b. Effects of dietary fat source and subtherapeutic levels of antibiotic on the bacterial community in the ileum of broiler chickens at various ages. Appl. Environ. Microbiol. 68:5918-5924.

Konstantinov, S. R., A. Awati, H. Smidt, B. A. Williams, A. D. L. Akkermans, and W. A. de Vos. 2004. Specific response of a novel and abundant Lactobacillus amylovorus-like phylotype to dietary prebiotics in the guts of weaning piglets. Appl. Environ. Microbiol. 70:3821-3830.

Kovatcheva-Datchary, P., M. Egert, A. Maathuis, M. Rajilic-Stojanovic, A. A. de Graaf, H. Smidt, W. M. de Vos, and K. Venema. 2009. Linking phylogenetic identities of bacteria to starch fermentation in an in vitro model of the large intestine by RNA-based stable isotope probing. Environ. Microbiol. 11:914-926.

Kunz, C., and S. Rudloff. 1993. Biological functions of oligosaccharides in human-milk. Acta Paediatr. 82:903-912.

Kurokawa, K., T. Itoh, T. Kuwahara, K. Oshima, H. Toh, A. Toyoda, H. Takami, H. Morita, V. K. Sharma, T. P. Srivastava, T. D. Taylor, H. Noguchi, H. Mori, Y. Ogura, D. S. Ehrlich, K. Itoh, T. Takagi, Y. Sakaki, T. Hayashi, and M. Hattori. 2007. Comparative metagenomics revealed commonly enriched gene sets in human gut microbiomes. DNA Res. 14:169-181.

\section{Leschelle, X., M. Goubern, M. Andriamihaja, H. Blottiere, E. Couplan, M. Gonzalez-} Barroso, C. Petit, A. Pagniez, C. Chaumontet, and B. Mignotte. 2005. Adaptative metabolic response of human colonic epithelial cells to the adverse effects of the luminal compound sulfide. Biochim. Biophys. Acta 1725:201-212. 
Leser, T. D., J. Z. Amenuvor, T. K. Jensen, R. H. Lindecrona, M. Boye, and K. Moller. 2002. Culture-independent analysis of gut bacteria: the pig gastrointestinal tract microbiota revisited. Appl. Environ. Microbiol. 68:673-690.

Ley, R. E., F. Backhed, P. Turnbaugh, C. A. Lozupone, R. D. Knight, and J. I. Gordon. 2005. Obesity alters gut microbial ecology. Proc. Natl. Acad. Sci. USA 102:11070_ 11075.

Ley, R. E., M. Hamady, C. Lozupone, P. J. Turnbaugh, R. R. Ramey, J. S. Bircher, M. L. Schlegel, T. A. Tucker, M. D. Schrenzel, R. Knight, and J. I. Gordon. 2008. Evolution of mammals and their gut microbes. Science 320:1647-1651.

Li, M., B. Wang, M. Zhang, M. Rantalainen, S. Wang, H. Zhou, Y. Zhang, J. Shen, X. Pang, M. Zhang, H. Wei, Y. Chen, H. Lu, J. Zuo, M. Su, Y. Qiu, W. Jia, C. Xiao, L. M. Smith, S. Yang, E. Holmes, H. Tang, G. Zhao, J. K. Nicholson, L. Li, and L. Zhao. 2008. Symbiotic gut microbes modulate human metabolic phenotypes. Proc. Natl. Acad. Sci. USA 105:2117-2122.

Lin, C. Z., and T. L. Miller. 1998. Phylogenetic analysis of Methanobrevibacter isolated from feces of humans and other animals. Arch. Microbiol. 169:397-403.

Lin, H., and W. Visek. 1991. Colon mucosal cell-damage by ammonia in rats. J. Nutr. 121:887893.

Lofmark, S., C. Jernberg, J. K. Jansson, and C. Edlund. 2006. Clindamycin-induced enrichment and long-term persistence of resistant Bacteroides spp. and resistance genes. J. Antimicrob. Chemother. 58:1160-1167.

Macfarlane, S., and G. T. Macfarlane. 1995. Proteolysis and amino acid fermentation. In G. R. Gibson and G. T. Macfarlane (ed.), Human Colonic Bacteria: Role in Nutrition, 
Physiology, and Pathology. CRC Press, Boca Raton, FL.

Mackie, R., A. Sghir, and H. Gaskins. 1999. Developmental microbial ecology of the neonatal gastrointestinal tract. Am. J. Clin. Nutr. 69:1035S-1045S.

Magee, E. A., C. J. Richardson, R. Hughes, and J. H. Cummings. 2000. Contribution of dietary protein to sulfide production in the large intestine: an in vitro and a controlled feeding study in humans. Am. J. Clin. Nutr. 72:1488-1494.

Mahowald, M. A., F. E. Rey, H. Seedorf, P. J. Turnbaugh, R. S. Fulton, A. Wollam, N. Shah, C. Y. Wang, V. Magrini, R. K. Wilson, B. L. Cantarel, P. M. Coutinho, B. Henrissat, L. W. Crock, A. Russell, N. C. Verberkmoes, R. L. Hettich, and J. I. Gordon. 2009. Characterizing a model human gut microbiota composed of members of its two dominant bacterial phyla. Proc. Natl. Acad. Sci. USA 106:5859-5864.

Mai, V. 2004. Dietary modification of the intestinal microbiota. Nutr. Rev. 62:235-242.

Marchesi, J. R., E. Holmes, F. Khan, S. Kochhar, P. Scanlan, F. Shanahan, I. D. Wilson, and Y. L. Wang. 2007. Rapid and noninvasive metabonomic characterization of inflammatory bowel disease. J. Proteome Res. 6:546-551.

Marchesi, J., and F. Shanahan. 2007. The normal intestinal microbiota. Curr. Opin. Infect. Dis. 20:508-513.

Martin, F. P., N. Sprenger, I. K. Yap, Y. Wang, R. Bibiloni, F. Rochat, S. Rezzi, C. Cherbut, S. Kochhar, J. C. Lindon, E. Holmes, and J. K. Nicholson. 2009. Panorganismal gut microbiome-host metabolic crosstalk. J. Proteome Res. 8:2090-2105.

Mazmanian, S. K., C. H. Liu, A. O. Tzianabos, and D. L. Kasper. 2005. An immunomodulatory molecule of symbiotic bacteria directs maturation of the host immune system. Cell 122:107-118. 
Morvan, B., F. Bonnemoy, G. Fonty, and P. Gouet. 1996. Quantitative determination of H-2utilizing acetogenic and sulfate-reducing bacteria and methanogenic archaea from digestive tract of different mammals. Curr. Microbiol. 32:129-133.

Naser, S. A., G. Ghobrial, C. Romero, and J. F. Valentine. 2004. Culture of Mycobacterium avium subspecies paratuberculosis from the blood of patients with Crohn's disease. Lancet 364:1039-1044.

Nicholson, J. K., E. Holmes, and I. D. Wilson. 2005. Gut microorganisms, mammalian metabolism and personalized health care. Nat. Rev. Microbiol. 3:431-438.

Ohene-Adjei, S., A. V. Chaves, T. A. McAllister, C. Benchaar, R. M. Teather, and R. J. Forster. 2008. Evidence of increased diversity of methanogenic archaea with plant extract supplementation. Microb. Ecol. 56:234-242.

Rajilic-Stojanovic, M., H. G. H. J. Heilig, D. Molenaar, K. Kajander, A. Surakka, H. Smidt, and W. M. de Vos. 2009. Development and application of the human intestinal tract chip, a phylogenetic microarray: analysis of universally conserved phylotypes in the abundant microbiota of young and elderly adults. Environ. Microbiol. 11:1736-1751.

Rawls, J. F., M. A. Mahowald, R. E. Ley, and J. I. Gordon. 2006. Reciprocal gut microbiota transplants from zebrafish and mice to germ-free recipients reveal host habitat selection. Cell 127:423-433.

Richards, J., J. Gong, and C. de Lange. 2005. The gastrointestinal microbiota and its role in monogastric nutrition and health with an emphasis on pigs: current understanding, possible modulations, and new technologies for ecological studies. Can. J. Anim. Sci. 85:421-435.

Rieu-Lesme, F., C. Delbes, and L Sollelis. 2005. Recovery of partial 16S rDNA sequences 
suggests the presence of Crenarchaeota in the human digestive ecosystem. Curr. Microbiol. 51:317-321.

Roos, S., and H. Jonsson. 2002. A high-molecular-mass cell-surface protein from Lactobacillus reuteri 1063 adheres to mucus components. Microbiology 148:433N442.

Rueda, R., J. Sabatel, J. Maldonaldo, J. Molina-Font, and A. Gil. 1998. Addition of gangliosides to an adapted milk formula modifies levels of fecal Escherichia coli in preterm newborn infants. J. Pediatr. 133:90-94.

Samuel, B. S., E. E. Hansen, J. K. Manchester, P. M. Coutinho, B. Henrissat, R. Fulton, P. Latreille, K. Kim, R. K. Wilson, and J. I. Gordon. 2007. Genomic and metabolic adaptations of Methanobrevibacter smithii to the human gut. Proc. Natl. Acad. Sci. USA 104:10643-10648.

Saxelin, M., S. Tynkkynen, T. Mattila-Sandholm, and W. M. de Vos. 2005. Probiotic and other functional microbes: from markets to mechanisms. Curr. Opin. Biotechnol. 16:204211.

Scanlan, P. D., and J. R. Marchesi. 2008. Micro-eukaryotic diversity of the human distal gut microbiota: qualitative assessment using culture-dependent and -independent analysis of faeces. ISME J. 2:1183-1193.

Schauser, K., and L. Larsson. 2005. Programmed cell death and cell extrusion in rat duodenum: a study of expression and activation of caspase-3 in relation to $\mathrm{C}$-jun phosphorylation, DNA fragmentation and apoptotic morphology. Histochem. Cell Biol. 124:237-243.

Schwiertz, A., B. Gruhl, M. Lobnitz, P. Michel, M. Radke, and M. Blaut. 2003. Development of the intestinal bacterial composition in hospitalized preterm infants in 
comparison with breast-fed, full-term infants. Pediatr. Res. 54:393-399.

Scupham, A. J., L. L. Presley, B. Wei, E. Bent, N. Griffith, M. McPherson, F. L. Zhu, O. Oluwadara, N. Rao, J. Braun, and J. Borenman. 2006. Abundant and diverse fungal microbiota in the murine intestine. Appl. Environ. Microbiol. 72:793-801.

Sears, C. 2005. A dynamic partnership: celebrating our gut flora. Anaerobe 11:247-251.

Sekirov, I., N. M. Tam, M. Jogova, M. L. Robertson, Y. L. Li, C. Lupp, and B. B. Finlay. 2008. Antibiotic-induced perturbations of the intestinal microbiota alter host susceptibility to enteric infection. Infect. Immun. 76:4726-4736.

Seksik, P., P. Lepage, M. F. de la Cochetiere, A. Bourreille, M. Sutren, J. P. Galmiche, J. Dore, and P. Marteau. 2005. Search for localized dysbiosis in Crohn's disease ulcerations by temporal temperature gradient gel electrophoresis of 16S rRNA. J. Clin. Microbiol. 43:4654-4658.

Servin, A. L. 2004. Antagonistic activities of lactobacilli and bifidobacteria against microbial pathogens. FEMS Microbiol. Rev. 28:405-440.

Shoemaker, N. B., H. Vlamakis, K. Hayes, and A. A. Salyers. 2001. Evidence for extensive resistance gene transfer among Bacteroides spp. and among Bacteroides and other genera in the human colon. Appl. Environ. Microbiol. 67:561-568.

\section{Sillanpaa, J., B. Martinez, J. Antikainen, T. Toba, N. Kalkkinen, S. Tankka, K.}

Lounatmaa, J. Keranen, M. Hook, B. Westerlund-Wikstrom, P. H. Pouwels, and T. K. Korhonen. 2000. Characterization of the collagen-binding S-layer protein CbsA of Lactobacillus crispatus. J. Bacteriol. 182:6440-6450.

Sogin, M. L., H. G. Morrison, J. A. Huber, D. Mark Welch, S. M. Huse, P. R. Neal, J. M. Arrieta, and G. J. Herndl. 2006. Microbial diversity in the deep sea and the 
underexplored "rare biosphere." Proc. Natl. Acad. Sci. USA 103:12115-12120.

Sokol, H., B. Pigneur, L. Watterlot, O. Lakhdari, L. G. Bermudez-Humaran, J. J.

Gratadoux, S. Blugeon, C. Bridonneau, J. P. Furet, G. Corthier, C. Grangette, N. Vasquez, P. Pochart, G. Trugnan, G. Thomas, H. M. Blottiere, J. Dore, P. Marteau, P. Seksik, and P. Langella. 2008. Faecalibacterium prausnitzii is an anti-inflammatory commensal bacterium identified by gut microbiota analysis of Crohn disease patients. Proc. Natl. Acad. Sci. USA 105:16731-16736.

Sonnenburg, J. L., C. T. Chen, and J. I. Gordon. 2006. Genomic and metabolic studies of the impact of probiotics on a model gut symbiont and host. PLoS Biol. 4:e413.

Sougioultzis, S., S. Simeonidis, K. Bhaskar, P. Anton, A. Pan, M. Warny, S. Aboudola, J.

Goldsmith, S. Keates, and C. Pothoulakis. 2003. Saccharomyces boulardii produces a soluble anti-inflammatory factor that inhibits NF-kappa B-mediated IL-8 gene expression. Gastroenterology 125:606-606.

Stark, P. L., and A. Lee. (1982). The microbial ecology of the large bowel of breast-fed and formula-fed infants during the first year of life. J. Med. Microbiol. 15:189-203.

Strocchi, A., J. Furne, C. Ellis, and M. D. Levitt. 1994. Methanogens outcompete sulfatereducing bacteria for H-2 in the human colon. Gut 35:1098-1101.

Swidsinski, A., V. Loening-Baucke, M. Vaneechoutte, and Y. Doerffel. 2008. Active Crohn's disease and ulcerative colitis can be specifically diagnosed and monitored based on the biostructure of the fecal flora. Inflamm. Bowel Dis. 14:147-161.

Swords, W., C. Wu, F. Champlin, and R. Buddington. 1993. Postnatal changes in selected bacterial groups of the pig colonic microflora. Biol. Neonate 63:191-200.

Tamboli, C. P., C. Neut, P. Desreumaux, and J. F. Colombel. 2004. Dysbiosis in 
inflammatory bowel disease. Gut 53:1-4.

Tanida, M., T. Yamano, K. Maeda, N. Okumura, Y. Fukushima, and K. Nagai. 2005. Effects of intraduodenal injection of Lactobacillus johnsonii Lal on renal sympathetic nerve activity and blood pressure in urethane-anesthetized rats. Neurosci. Lett. 389:109114.

Tannock, G., R. Fuller, and K. Pedersen. 1990a. Lactobacillus succession in the piglet digestive-tract demonstrated by plasmid profiling. Appl. Environ. Microbiol. 56:13101316.

Tannock, G., R. Fuller, S. Smith, and M. Hall. 1990b. Plasmid profiling of members of the family enterobacteriaceae, lactobacilli, and bifidobacteria to study the transmission of bacteria from mother to infant. J. Clin. Microbiol. 28:1225-1228.

Tap, J., S. Mondot, F. Levenez, E. Pelletier, C. Caron, J. P. Furet, E. Ugarte, R. MunozTamayo, D. L. Paslier, R. Nalin, J. Dore, and M. Leclerc. 2009. Towards the human intestinal microbiota phylogenetic core. Environ. Microbiol. 11:2574-2584.

Thoreux, K., D. Balas, C. Bouley, and F. Senegas-Balas. 1998. Diet supplemented with yoghurt or milk fermented by Lactobacillus casei DN-114 001 stimulates growth and brush-border enzyme activities in mouse small intestine. Digestion 59:349-359.

Trompette, A., J. Claustre, F. Caillon, G. Jourdan, J.A. Chayvialle, and P. Plaisancie. 2003. Milk bioactive peptides and beta-casomorphins induce mucus release in rat jejunum. $J$. Nutr. 133:3499-3503.

Turnbaugh, P. J., M. Hamady, T. Yatsunenko, B. L. Cantarel, A. Duncan, R. E. Ley, M. L. Sogin, W. J. Jones, B. A. Roe, J. P. Affourtit, M. Egholm, B. Henrissat, A. C. Heath, R. Knight, and J. I. Gordon. 2009. A core gut microbiome in obese and lean twins. 
Nature 457:480-484.

Turnbaugh, P. J., R. E. Ley, M. A. Mahowald, V. Magrini, E. R. Mardis, and J. I. Gordon. 2006. An obesity-associated gut microbiome with increased capacity for energy harvest. Nature 444:1027-1031.

Umesaki, Y., Y. Okada, S. Matsumoto, A. Imaoka, and H. Setoyama. 1995. Segmented filamentous bacteria are indigenous intestinal bacteria that activate intraepithelial lymphocytes and induce MHC class-II molecules and fucosyl asialo Gm1 glycolipids on the small-intestinal epithelial-cells in the ex-germ-free Mouse. Microbiol. Immunol. 39:555-562.

van der Wielen, P. W. J. J., S. Biesterveld, S. Notermans, H. Hofstra, B. A. P. Urlings, and F. van Knapen. 2000. Role of Volatile Fatty acids in development of the cecal microflora in broiler chickens during growth. Appl. Environ. Microbiol. 66:2536-2540.

Van Loo, J. A. 2004. Prebiotics promote good health: the basis, the potential, and the emerging evidence. J. Clin. Gastroenterol. 38:S70-75.

Van Nuenen, M., K. Venema, J. Van der Woude, and E. Kuipers. 2004. The metabolic activity of fecal microbiota from healthy individuals and patients with inflammatory bowel disease. Digest. Dis. Sci. 49:485-491.

Verberkmoes, N. C., A. L. Russell, M. Shah, A. Godzik, M. Rosenquist, J. Halfvarson, M. G. Lefsrud, J. Apajalahti, C. Tysk, R. L. Hettich, and J. K. Jansson. 2009. Shotgun metaproteomics of the human distal gut microbiota. ISME J. 3:179-189.

Walker, A. 2007. Genome watch - say hello to our little friends. Nat. Rev. Microbiol. 5:572573.

Wanitschke, R., and H. Ammon. 1978. Effects of dihydroxy bile-acids and hydroxy fatty-acids 
on absorption of oleic-acid in human jejunum. J. Clin. Invest. 61:178-186.

Wikoff, W. R., A. T. Anfora, J. Liu, P. G. Schultz, S. A. Lesley, E. C. Peters, and G. Siuzdak. 2009. Metabolomics analysis reveals large effects of gut microflora on mammalian blood metabolites. Proc. Natl. Acad. Sci. USA 106:3698-3703.

Willing, B., J. Halfvarson, J. Dicksved, M. Rosenquist, G. Jarnerot, L. Engstrand, C. Tysk, and J. K. Jansson. 2009a. Twin studies reveal specific imbalances in the mucosaassociated microbiota of patients with ileal Crohn's disease. Inflamm. Bowel Dis. 15:653660.

Willing, B., A. Vörös, S. Roos, C. Jones, A. Jansson, and J. E. Lindberg. 2009b. Changes in faecal bacteria associated with concentrate and forage-only diets fed to horses in training. Equine Vet. J. 41:908-915.

Willing, B. P., and B. B. Finlay. 2009. Gut microbiology: fitting into the intestinal neighbourhood. Curr. Biol. 19:R457-459.

Woese, C. R., O. Kandler, and M. L. Wheelis. 1990. Towards a natural system of organisms proposal for the domains Archaea, Bacteria, and Eucarya. Proc. Natl. Acad. Sci. USA 87:4576-4579.

Xu, J., M. A. Mahowald, R. E. Ley, C. A. Lozupone, M. Hamady, E. C. Martens, B. Henrissat, P. M. Coutinho, P. Minx, P. Latreille, H. Cordum, A. Van Brunt, K. Kim, R. S. Fulton, L. A. Fulton, S. W. Clifton, R. K. Wilson, R. D. Knight, and J. I. Gordon. 2007. Evolution of symbiotic bacteria in the distal human intestine. PLOS Biol. 5:e156.

Yap, I. K., J. V. Li, J. Saric, F. P. Martin, H. Davies, Y. Wang, I. D. Wilson, J. K. Nicholson, J. Utzinger, J. R. Marchesi, and E. Holmes. 2008. Metabonomic and 
microbiological analysis of the dynamic effect of vancomycin-induced gut microbiota modification in the mouse. J. Proteome Res. 7:3718-3728.

Yergeau, E., S. A. Schoondermark-Stolk, E. L. Brodie, S. Dejean, T. Z. DeSantis, O. Goncalves, Y. M. Piceno, G. L. Andersen, and G. A. Kowalchuk. 2009. Environmental microarray analyses of Antarctic soil microbial communities. ISME J. 3:340-351.

Yokoyama, M. T., C. Tabori, E. R. Miller, and M. G. Hogberg. 1982. The effects of antibiotics in the weanling pig diet on growth and the excretion of volatile phenolic and aromatic bacterial metabolites. Am. J. Clin. Nutr. 35:1417-1424.

Zoetendal, E. G., A. D. L. Akkermans, W. M. Akkermans-van Vliet, J. Arjan, G. M. de Visser, and W. M. de Vos. 2001. The host genotype affects the bacterial community in the human gastrointestinal tract. Microb. Ecol. 13:129-134.

Zoetendal, E. G., C. T. Collier, S. Koike, R. I. Mackie, and H. R. Gaskins. 2004. Molecular ecological analysis of the gastrointestinal microbiota: a review. J. Nutr. 134:465-472.

Zoghbi, S., A. Trompette, J. Claustre, M. El Homsi, J. Garzon, J. Y. Scoazec, and P. Plaisancie. 2006. beta-Casomorphin-7 regulates the secretion and expression of gastrointestinal mucins through a mu-opioid pathway. Am. J. Physiol. Gastrointest. Liver Physiol. 290:G1105-G1113. 
$<$ TN $>$ TABLE $1<$ TT $>$ Representation of classified bacterial phyla from 60 mammalian species ${ }^{a}$

\begin{tabular}{|l|c|}
\hline KT-1 $>$ Phylum & \% of classified sequences \\
\hline KTB $>$ Firmicutes & 65.7 \\
\hline Bacteroidetes & 16.3 \\
\hline Proteobacteria & 8.8 \\
\hline Actinobacteria & 4.7 \\
\hline Verrucomicrobia & 2.2 \\
\hline Fusobacteria & 0.67 \\
\hline Spirochaetes & 0.46 \\
\hline DSS1 & 0.35 \\
\hline Fibrobacters & 0.13 \\
\hline TM7 & 0.13 \\
\hline Cyanobacteria & 0.1 \\
\hline Planctomycetes & 0.08 \\
\hline Deferribacteres & 0.05 \\
\hline Lentisphaerae & 0.04 \\
\hline Chloroflexi & 0.005 \\
\hline SR1 & 0.005 \\
\hline Deinococcus-Thermus & 0.005 \\
\hline
\end{tabular}

$<\mathrm{TFN}>^{a}$ Adapted from Ley et al., 2008. 
FIGURE 1. Overview of "omics" approaches to study the gut microbiota.

FIGURE 2. Functional redundancy of the gut microbiota suggested by large variations in community composition between individuals: (A) compared to community functions or (B) categories of gene function. Reprinted from Turnbaugh et al. (2009), with permission.

FIGURE 3. Bacterial colonization of the GI tract. Bacterial numbers increase in abundance from proximal to distal regions. Bacteria reside in close proximity to the intestinal epithelium. A firmly adherent layer of mucous keeps bacteria at a safe distance so as to prevent continual mucosal stimulation and inflammation and a loosely adherent layer provides a habitat for abundant microbial colonization.

FIGURE 4. Synergistic action of bacteria in degradation of carbohydrates. Different bacterial species work together in the metabolism of dietary carbohydrate, each contributing to the process.

FIGURE 5. A representation of $B$. thetaiotaomicron and E. rectale colonizing the gastrointestinal tract of the mouse alone $(\mathrm{A}, \mathrm{B})$ or together $(\mathrm{C})$. Interactions between bacteria result in changes in bacterial physiology and how they affect the host. Competition with $E$. rectale for nutrients causes $B$. thetaiotaomicron to stimulate the production of glycans from the host that it, but not $E$. rectale, can utilize. E. rectale utilizes acetylCoA produced by $B$. thetaiotaomicron resulting in an increased production of butyrate. The interactions between bacteria, including competition and synergistic interactions, result in an amplified host response. Adapted from Willing and Finlay (2009). 


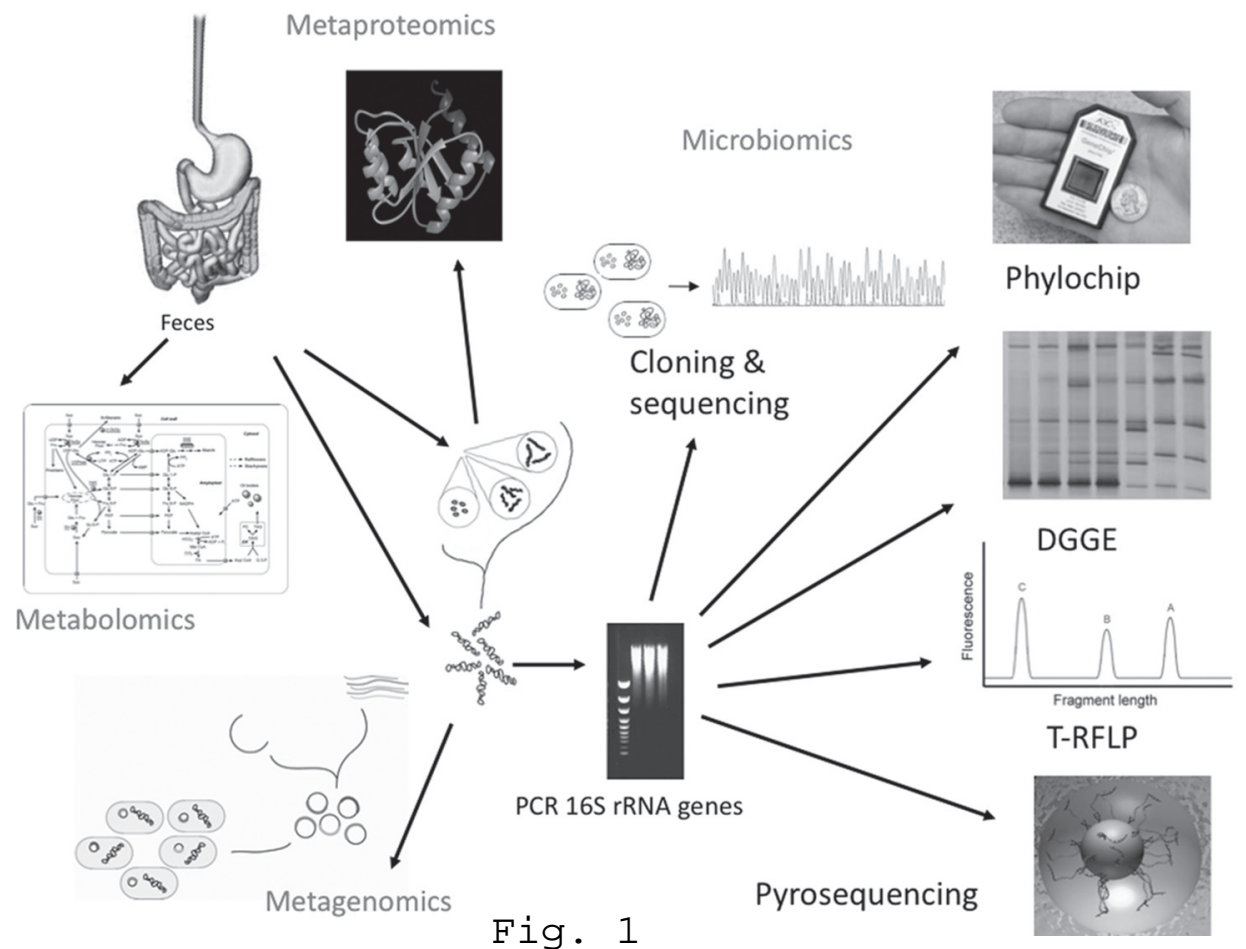




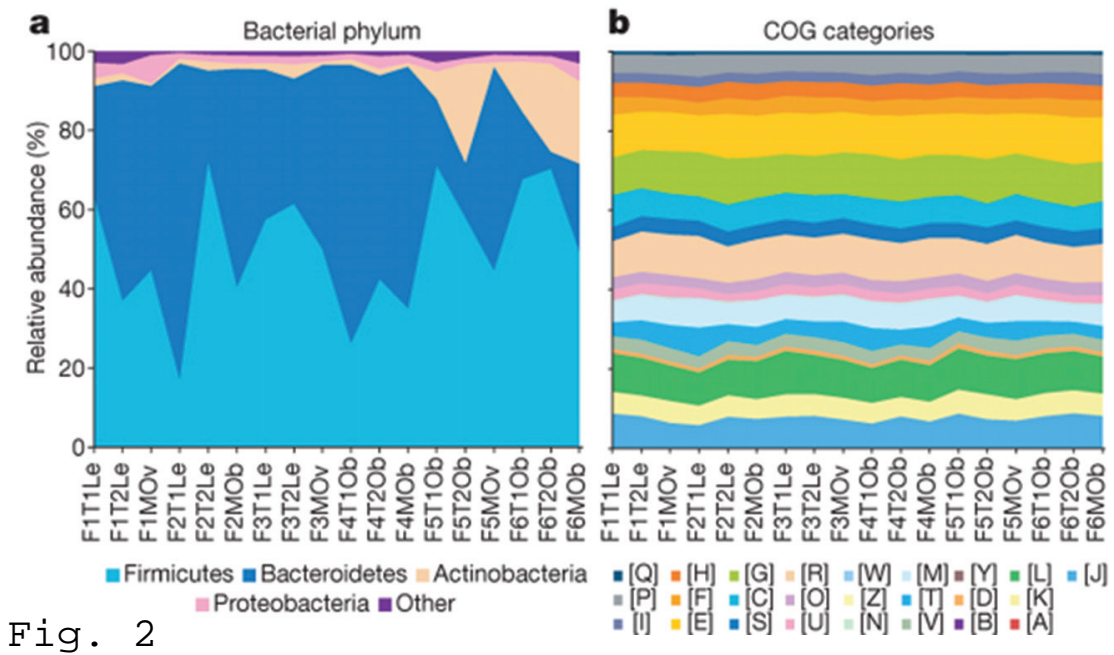




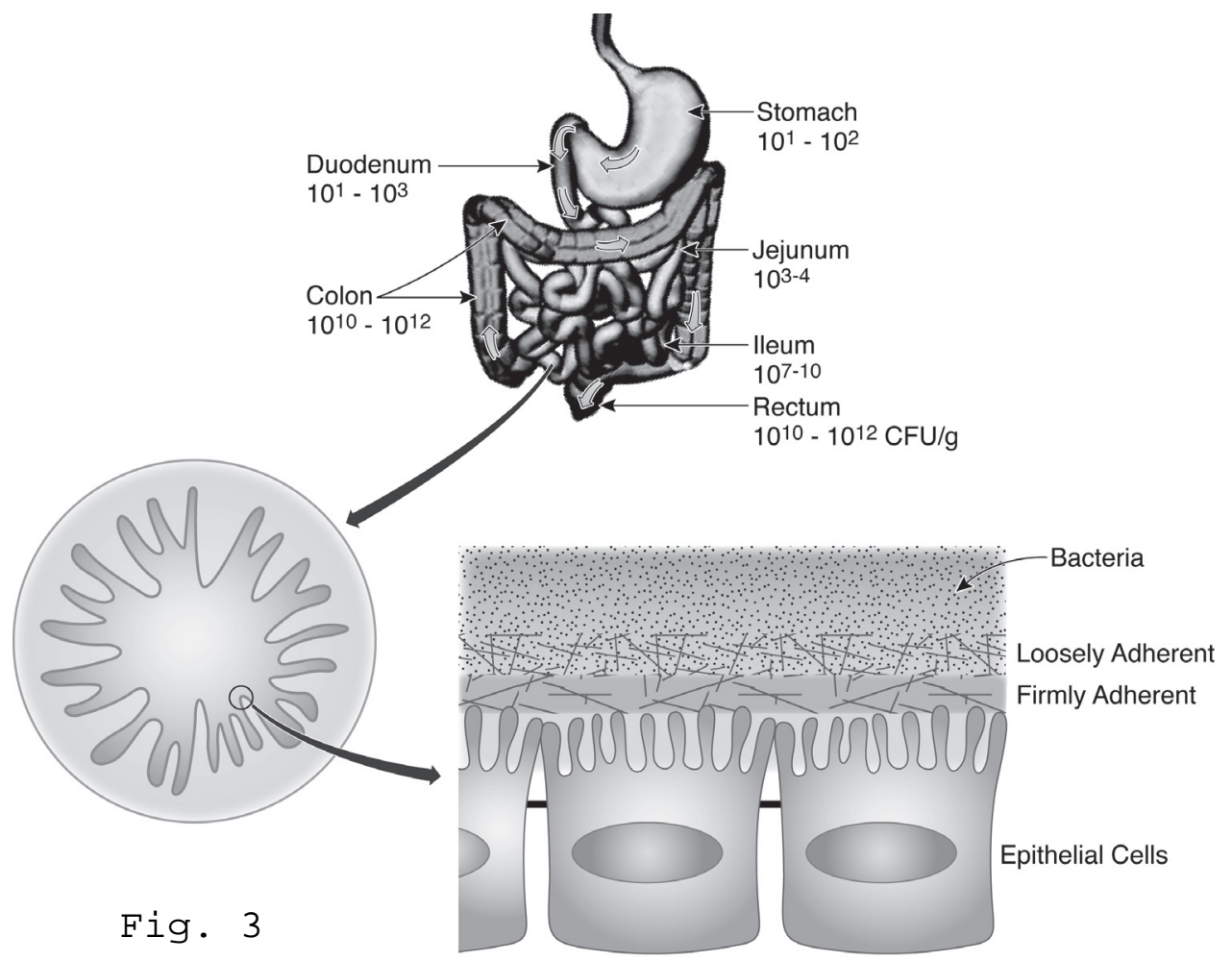




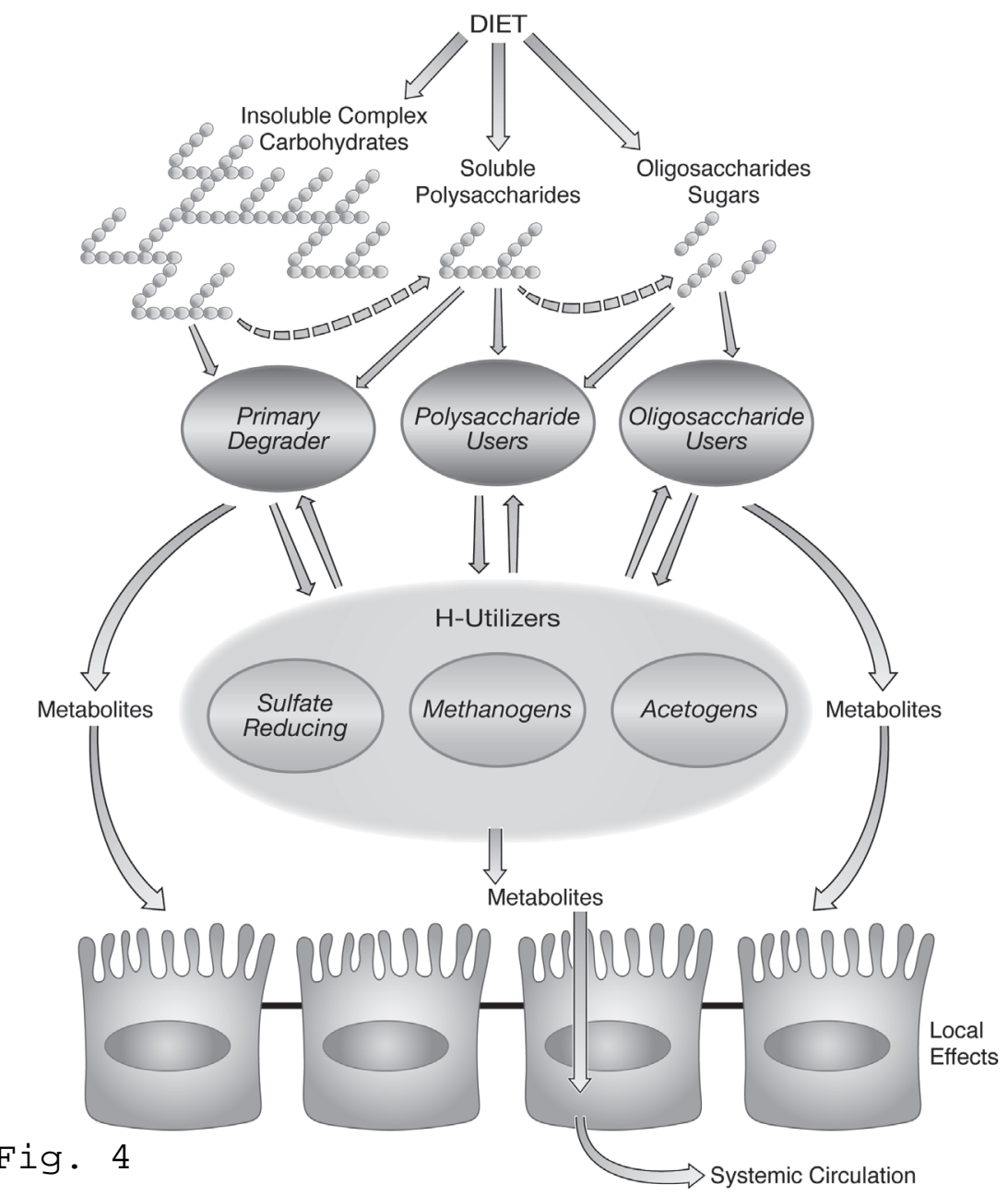



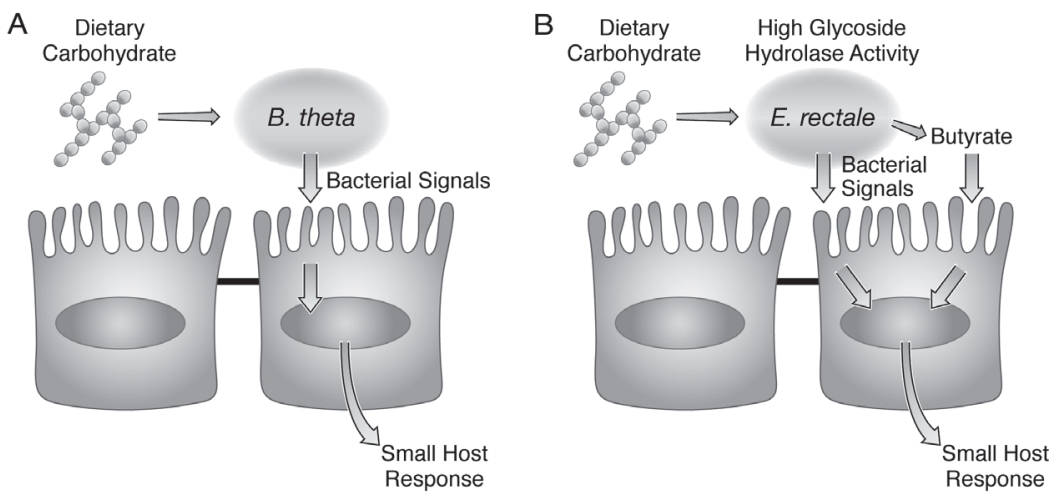

C

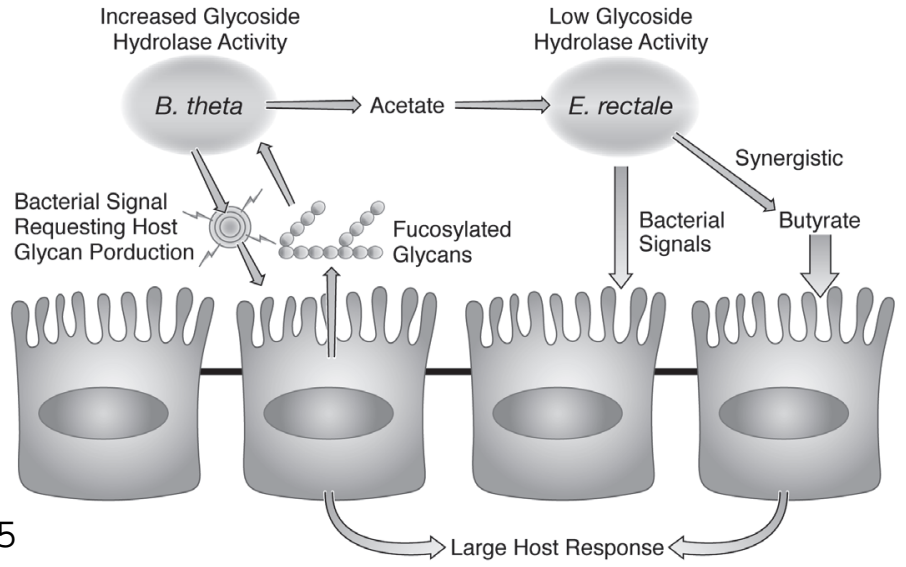

Fig. 5 